\title{
Resveratrol induces brain resilience against Alzheimer neurodegeneration through proteostasis enhancement
}

Rubén Corpas ${ }^{1}$, Christian Griñán-Ferré ${ }^{2}$, Eduard Rodríguez-Farré ${ }^{1,3}$, Mercè Pallàs ${ }^{2}$ and Coral Sanfeliu ${ }^{1,3}$

${ }^{1}$ Institut d'Investigacions Biomèdiques de Barcelona (IIBB), CSIC and IDIBAPS, Barcelona, Spain

${ }^{2}$ Faculty of Pharmacy, Institut de Neurociències, Universitat de Barcelona and CIBERNED, Barcelona, Spain

${ }^{3}$ CIBER Epidemiología y Salud Pública (CIBERESP), Spain

\section{Corresponding authors:}

Rubén Corpas,

IIBB-CSIC

C/Rosselló 161, 6th floor, 08036 Barcelona, Spain

E-mail address: ruben.corpas@iibb.csic.es

Tel.: (+34) 933638377

Coral Sanfeliu,

IIBB-CSIC, IDIBAPS, CIBERESP

C/Rosselló 161, 6th floor, 08036 Barcelona, Spain

E-mail address: coral.sanfeliu@iibb.csic.es

Tel.: (+34) 933638338 


\section{Abstract}

2 Resveratrol is a natural compound that mimics the antioxidant and antiaging effects of caloric restriction, mainly mediated through SIRT1, a deacetylase that induces longevity and neuroprotection. We aimed to analyze the effects of resveratrol on the brain status of control non-transgenic (NoTg) and AD transgenic (3xTg-AD) mice to discern the mechanisms involved in a potential inducement of resilience against age-related neurodegeneration and Alzheimer's disease (AD). Mice were fed with a diet supplemented with $100 \mathrm{mg} / \mathrm{kg}$ of trans-resveratrol from 2 months of age during 10 months. Resveratrol administration induced complete protection against memory loss and brain pathology in 3xTg$\mathrm{AD}$ mice, and also induced cognitive enhancement in healthy NoTg mice. Resveratrol improved exploration and reduced anxiety in both mouse strains, indicative of well-being. Resveratrol reduced the presence of $A \beta$ and p-tau pathology in the hippocampus of the 3xTg-AD mouse. Proteostasis analysis showed the following in both NoTg and 3xTg-AD mice: (i) increased levels of the amyloid degrading enzyme neprilysin; (ii) reduction of the amyloidogenic secretase BACE1, and (iii) increase of proteasome protein levels and enhancement of proteasome activity. Resveratrol also increased AMPK protein levels, then upregulating the SIRT1 pathway, as shown by the activation of PGC-1 $\alpha$ and CREB in both mice, resulting in further beneficial changes. Our data demonstrated that resveratrol induces cognitive enhancement and neuroprotection against amyloid and tau pathologies. Improvement of proteostasis by resveratrol, in both healthy and $\mathrm{AD}$ mice, suggests that it is a mechanism of brain resilience and defense against neurodegeneration caused by the accumulation of aberrant proteins.

\section{Keywords}

20 Resveratrol, SIRT1, proteasome, neuroprotection, 3xTg-AD

\section{Abbreviations}

$\mathrm{A} \beta$, amyloid- $\beta$; $\mathrm{AD}$, Alzheimer's disease; ADAM10, a disintegrin and metalloproteinase 10; ANOVA, analysis of variance; AMPK, adenosine monophosphate-activated protein kinase; p-AMPK, phosphorylated AMPK; APP, amyloid precursor protein; APP-CTF, C-terminal fragment of APP; bw, body weight; BACE1, beta-site APP cleaving enzyme 1; BPSD, behavioral and psychological symptoms of dementia; CHIP, carboxyl-terminus of Hsp70 interacting protein; CREB, cAMP response element-binding protein; p-CREB, phosphorylated CREB; CSF, cerebrospinal fluid; Hsp70, heat shock protein 70; IDE, insulin-degrading enzyme; MWM, Morris water maze; $\mathrm{NAD}^{+}$, nicotinamide-adenine dinucleotide; NOR, novel object recognition; NoTg, control non-transgenic mice; ac-p53, acetylated p53; PGC-1 $\alpha$, peroxisome proliferator-activated receptor- $\gamma$ coactivator $1 \alpha$; PSD95, postsynaptic density protein 95 ; ac-tau, acetylated tau; p-tau, hyperphosphorylated tau; UPS, ubiquitin proteasome system. 


\section{Introduction}

The progressive increase in life expectancy has led to an increase in the incidence of age-related diseases, including dementia [1]. Alzheimer's disease (AD) is the most common cause of dementia in the elderly [2,3], characterized by brain depositions of amyloid- $\beta(A \beta)$ and hyperphosphorylated tau (p-tau), leading to synapse dysfunction, cognitive and memory deficits and, finally death [4,5]. To date, there is no effective treatment of $\mathrm{AD}$, except for temporarily symptom-relieving drugs [6,7]. Finding a treatment is crucial to reducing the overall effects of aging, increasing healthspan in humans.

Resveratrol is a polyphenol found in common dietary sources such as grapes, berries, peanuts and red wine, and in some herbal remedies [8,9]. In animal models, resveratrol exhibits a wide spectrum of potential therapeutic activities, including antioxidant, anti-inflammatory, neuroprotective and longevity-promoting properties [9-11]. Experimental studies suggest that resveratrol is active against AD pathogenesis [12-15]. First clinical trials of dietary supplementation with resveratrol in $\mathrm{AD}$ have been completed, with encouraging changes such as attenuation of the decline of cerebrospinal fluid (CSF) levels of $A \beta$ species [16,17], and reduction of plasma levels of pro-inflammatory markers and attenuation of cognitive and functional decline [17]. Furthermore, improvement of cognitive performance reported in trials with non-demented older adults [18,19] suggests a preventive potential of resveratrol. Studies with transgenic mouse models of AD showed that resveratrol intake protected against A $\beta$ plaque formation in Tg19959 [20] and APP/PS1 mice [21,22]. Increased synaptic markers and preservation of recognition memory were also found in resveratrol treated APP/PS1 mice [22]. Moreover, in the p25 mouse model of AD and tauopathies, intracerebroventricular delivery of resveratrol prevented impairment of fear conditioning associative learning and reduced the levels of markers of apoptosis and astrogliosis [23].

The hypothesis of the most widely accepted mechanism comprises that resveratrol mimics the antioxidant and antiaging effects of caloric restriction [24,25], which are mediated by SIRT1 [22,26]. SIRT1 is a nicotinamide-adenine dinucleotide $\left(\mathrm{NAD}^{+}\right)$-dependent deacetylase associated with anti-aging pathways [27] that induces protective effects against $\mathrm{AD}$ brain pathology through regulating the acetylation homeostasis of key proteins [28-30]. There is controversy over whether resveratrol may be a direct activator of SIRT1 [31] or whether SIRT1 is indirectly activated by other resveratrol-induced pathways [32,33]. Recent evidences suggest that resveratrol increases adenosine monophosphate-activated protein kinase (AMPK) activity, leading to an increase of $\mathrm{NAD}^{+}$levels, which in turn enhances SIRT1 activity [34,35].

At the cellular level, resveratrol demonstrated protective effects against oxidative stress and inflammatory processes induced by $\mathrm{A} \beta$ in $\mathrm{PC} 12$ cell line [36] and human stem cells [37]. Resveratrol promotes $\mathrm{A} \beta$ clearance through enhancement of proteasome-dependent proteolysis, as shown in cell lines expressing APP695, either wild-type or harboring the Swedish mutation [38] and in a C.elegans model of AD [39]. Resveratrol was also shown reducing A $\beta$ levels of transgenic cell line and worm models by autophagy and lysosomal degradation activated by AMPK signaling [21,39]. Furthermore, resveratrol may decrease A $\beta$ generation by favoring the non-amyloidogenic pathway of APP degradation [26].

One of the molecular changes of aging that might contribute to the development of $\mathrm{AD}$ is the deficiency in cellular control mechanisms that degrade aberrant proteins [40]. Clearance of $A \beta$ and tau through proteolytic mechanisms include ubiquitin-proteasome system (UPS), autophagy-lysosomal system, and extracellular proteases [41]. Furthermore, protein folding stress in the endoplasmic reticulum may activate the unfolded protein response aimed to restore proteostasis, preferentially through autophagy in the AD brain [42], or trigger apoptosis of irreversible damaged cells [43]. However, the stress responsivity of the different AD mouse models is highly variable [44]. UPS is the 
74 primary selective mechanism to maintain proteostasis in eukaryotic cells and is involved in many nerve cell functions, 75 such as plasticity and memory [45,46]. Increasing evidence postulates functional alterations of UPS and its molecular 76 components as causes of early changes in AD pathology [47]. Heat shock protein 70 (Hsp70) facilitates the 77 ubiquitination of aberrant proteins through interaction with the carboxyl-terminus of Hsp70 interacting protein (CHIP) 78 and the E3 ligase [48]. Polyubiquitinated proteins are recognized by the proteasome complex for subsequent proteolytic 79 degradation by the $20 \mathrm{~S}$ catalytic core $[49,50]$.

80 Studies with AD mouse models were needed to confirm resveratrol-induced cognitive improvement and further unveil 81 its mechanism of action against AD-like neurodegeneration. We aimed to analyze the effects of the administration of 82 resveratrol in mice as a preventive and therapeutic agent, with emphasis in APP processing and UPS activity, and their 83 effects on learning and memory. For this purpose, we treated both control non-transgenic mice (NoTg) and triple84 transgenic mice for $\mathrm{AD}(3 \mathrm{xTg}-\mathrm{AD})$ with a daily dose of $100 \mathrm{mg} / \mathrm{kg}$ of resveratrol during 10 months. Our results 85 demonstrated that resveratrol administration induced complete protection against memory loss and brain pathology in 86 AD mice. Furthermore, we showed that resveratrol induced proteostasis enhancement in both 3xTg-AD and healthy 87 NoTg mice. We propose that proteostasis enhancement increases brain resilience against neurodegeneration. New 88 insights into the mechanisms of resveratrol in preclinical studies may aid in the design of preventive strategies against 89 AD. 
Animals

Male 3xTg-AD mouse strain harboring familial AD mutations of the APP ( $\left.\mathrm{APP}_{\text {Swe }}\right)$ and the Presenilin $1\left(\mathrm{PS} 1_{\mathrm{M} 146 \mathrm{~V}}\right)$, and a tau gene mutation (Tau ${ }_{\mathrm{P} 301 \mathrm{~L}}$ ) [51] was used in the present study. These mice mimic many of the critical hallmarks of $\mathrm{AD}$ as $\mathrm{A} \beta$ and tau pathologies, impaired learning and memory, presence of behavioral and psychological symptoms of dementia (BPSD)-like, and oxidative stress [30,52]. Furthermore, 3xTg-AD mice reproduce the temporal course and areas affected by amyloid and tau pathology of AD neuropathology [53]. Control NoTg mice had the same genetic background hybrid $129 \times$ C57BL/6 than 3xTg-AD mice [51]. Genotypes were confirmed by PCR analysis of DNA obtained from tail biopsies. Animals were individually housed in Makrolon ${ }^{\circledR}$ cages under standard laboratory conditions of food and water ad libitum, $22 \pm 2{ }^{\circ} \mathrm{C}$, and $12 \mathrm{~h}$ : $12 \mathrm{~h}$ light-dark cycle. Animal breeding, treatment, and behavioral studies were performed at the University of Barcelona Animal House (UB, Barcelona, Spain). Animal handling and experimental procedures were approved by the Ethics Committee for animal experimentation (CEEA) of the University of Barcelona (UB) (Ref: DAAM 6523, CEEA), in accordance with the Decree 214/1997 of the Generalitat of Catalonia and the Directive 2010/63/EU of the European Union for animal experiments.

\section{Resveratrol administration}

At 2 months of age, mouse standard diet (2018 Teklad Global $18 \%$ Protein Rodent Maintenance Diet, Harlan) was supplemented with $1 \mathrm{~g} / \mathrm{kg}$ of trans-resveratrol (Mega Resveratrol, Candlewood Stars, Inc., CT, USA). Resveratrol groups (RV) received $100 \mathrm{mg} / \mathrm{kg}$ bw/day during 10 months. The period of 2 to 12 months of age covers a broad period of the $\mathrm{AD}$ pathology progression in $3 \mathrm{xTg}-\mathrm{AD}$ mice, from the pre-symptomatic to the advanced pathology phase. Control groups $(\mathrm{Ct})$ received standard diet. The experimental groups were as follows: $\operatorname{NoTg}-\mathrm{Ct}(\mathrm{n}=14), \operatorname{NoTg}-\mathrm{RV}(\mathrm{n}=$ $12), 3 \times T g-C t(n=10)$ y $3 \times T g-R V(n=10)$. No significant differences were found among the treatment groups in diet intake or in body weight along the study (not shown).

\section{Behavioral and cognitive tests}

Animals were tested for behavior and cognitive improvement at 10 months of the chronic resveratrol treatment, at 12 months of age. The behavioral tests were carried out at the Unitat d'Experimentació Animal of the Faculty of Psychology of the University of Barcelona (Campus Mundet, UB). Selected BPSD-like symptoms and cognitive tests were analyzed as previously described [54,55]. Briefly, the Open field test was used to evaluate vertical and horizontal locomotor activity and general behavior in a white chamber during $5 \mathrm{~min}$. The Boissier's 4 hole-board test was utilized to evaluate exploratory behavior by measuring head-dipping during $5 \mathrm{~min}$. The Dark \& Light test was employed to assess anxiety during $5 \mathrm{~min}$ in a black compartment connected to a lit compartment. The Novel object recognition (NOR) test was used to evaluate recognition memory, and is based on the spontaneous tendency of rodents to spend more time exploring a novel object than a familiar one. The animals were submitted to a 10 min acquisition trial in the presence of two identical novel objects $(\mathrm{A} 1+\mathrm{A} 2)$. A 10 min retention trial occurred $2 \mathrm{~h}$ later, replacing object A1 with object $\mathrm{B}$; and another $10 \mathrm{~min}$ retention trial took place $24 \mathrm{~h}$ later, replacing object A2 with object $\mathrm{C}$. Discrimination index was calculated as [novel ( $\mathrm{t}$ - familiar (t)] / [total time ( $\mathrm{t}$ ) at novel + familiar]. The Morris water maze (MWM) test was employed to assess spatial learning and memory, and consisted of 1 day of cue learning, 6 days of learning acquisition, and 1 final day of memory retrieval. Animals were trained to locate the hidden platform in a circular water 
platform was removed and the mice performed a $60 \mathrm{sec}$ probe trial to test learning retention. A computerized tracking system (SMART, Panlab S.A., Barcelona, Spain) was employed to measure escape latency, and distances and quadrants covered. At the end of the behavioral tests, the animals were decapitated under light anesthesia and the hippocampus and cerebral cortex were dissected and stored at $-80^{\circ} \mathrm{C}$ for further analysis.

\section{Western blotting}

Protein extracts from hippocampus and cerebral cortex were obtained in $50 \mathrm{mM}$ Tris/ $\mathrm{HCl}(\mathrm{pH}$ 7.6), $150 \mathrm{mM} \mathrm{NaCl}, 1 \%$ Triton X-100, $1 \mathrm{mM}$ phenylmethylsulfonyl fluoride, $1 \mathrm{mM}$ dithiothreitol and $10 \mu \mathrm{g} / \mathrm{mL}$ aprotinin. Aliquots of $30 \mu \mathrm{g}$ of protein were analyzed for Western blot analysis by standard procedures [30,56]. The following antibodies were employed for immunodetection: A $\beta$ clone 6e10, sAPP $\alpha$, sAPP $\beta$, C-terminal fragment of APP (APP-CTF), a disintegrin and metalloproteinase 10 (ADAM10), AMPK, phosphorylated AMPK (p-AMPK), beta-site APP cleaving enzyme 1 (BACE1), cAMP response element-binding protein (CREB), phosphorylated CREB (p-CREB), Hsp70, IDE, neprilysin, acetylated p53 (ac-p53), peroxisome proliferator-activated receptor- $\gamma$ coactivator $1 \alpha$ (PGC-1 $\alpha$ ), proteasome $20 \mathrm{~S}$ core subunits, postsynaptic density protein 95 (PSD95), SIRT1, synaptophysin, acetylated tau (ac-tau), p-tau clone AT8, total tau clone HT7, and ubiquitin. Details of primary antibodies used are presented in Supplementary Table 1. Secondary antibodies were peroxidase-conjugated (1:2000) (GE Healthcare). Quantitative values of the correspondent bands were detected by a chemiluminiscence method using VersaDoc Imaging System 5000 (Bio-Rad, USA). Optical density of the studied proteins was normalized to actin or tubulin. Protein levels were calculated and expressed relative to the amount in the NoTg-Ct mouse group.

\section{Proteasome activity assay}

Proteasomal activity was evaluated in the brain cortex by the Proteasome-Glo ${ }^{\mathrm{TM}}$ Assay Systems (Promega, USA). Cortex tissues in ice-cold PBSE (PBS, 5 mM EDTA, pH 7.4) at a ratio of 1:10 (buffer/tissue; v/w) were sonicated on ice for $20 \mathrm{sec}$ with a $1 \mathrm{sec}$ pulse length, twice, using a pulsed homogenizer. Obtained tissue lysates were centrifuged at $13,000 \mathrm{~g}$ for $10 \mathrm{~min}$ at $4^{\circ} \mathrm{C}$, and the supernatants were subjected to protein quantification employing the Bradford assay. The supernatants were diluted with cold PBSE at a concentration of $0.2 \mathrm{mg} / \mathrm{ml}$ total protein. A total of $10 \mu \mathrm{g}$ of protein ( $50 \mu \mathrm{l}$ of $0.2 \mathrm{mg} / \mathrm{ml}$ diluted extract) was added to $50 \mu \mathrm{l}$ of the luminescent reagent containing the Ultra-Glo ${ }^{\mathrm{TM}}$ Luciferase and the specific luminogenic substrate (Suc-LLVY-GloTM for the chymotrypsin-like activity assay, Z-LRR$\mathrm{Glo}^{\mathrm{TM}}$ for the trypsin-like activity assay, or Z-nLPnLD-Glo ${ }^{\mathrm{TM}}$ for the caspase-like activity assay) in a 96-well plate. Solutions were mixed for $30 \mathrm{sec}$ at $400 \mathrm{rpm}$ and incubated for $30 \mathrm{~min}$ at room temperature. The resulting luminescence was measured twice with an integration time of $1 \mathrm{sec}$ utilizing the Orion II Microplate Luminometer (Titertek-Berthold, Germany). In this setup, luminescence signal intensity corresponded to proteasomal proteolytic activity. The proteasomal inhibitor was used (MG-132, $10 \mu \mathrm{M}$ ) to calculate unspecific background activity.

\section{Statistical analysis}

Results are expressed as mean \pm SEM. Data were analyzed with analysis of variance (ANOVA) procedures; factors were genotype and treatment. Two-way repeated measures ANOVA was employed to analyze the acquisition task of the MWM test. All other data were analyzed by regular two-way ANOVA followed by main effect analysis for comparison of groups where interaction between factors was present. Statistical analyses were performed using 


\section{Results}

\section{Resveratrol administration induced beneficial effects on BPSD-like behavior}

Ten-month resveratrol treatment induced a significant protective effect against the AD-like pathology underlying BPSD-like behavioral alterations in 12 month-old mice (Fig. 1a-e). In the Open field test, 3xTg-Ct mice demonstrated lower vertical explorations (rearings) compared to NoTg mice (Fig. 1a). Resveratrol administration increased the number of total rearings in both NoTg-RV and 3xTg-RV mice [genotype, $\mathrm{F}(1,39)=48.29$, $\mathrm{p}<0.0001$; and treatment, $\mathrm{F}(1,39)=4.219, \mathrm{p}=0.0467]$. Moreover, 3xTg-Ct mice showed lower horizontal mobility compared to NoTg mice (Fig. 1b). Resveratrol treatment also increased the total distance covered in both strains [genotype, $\mathrm{F}(1,42)=40.75$, $\mathrm{p}<$ 0.0001; and treatment, $\mathrm{F}(1,42)=7.343, \mathrm{p}=0.0097$ ]. In the Boissier's 4 hole-board test, 3xTg-Ct mice showed higher latency for first-hole exploration compared to NoTg mice (Fig. 1c). Resveratrol treatment reduced latency in both NoTg-RV and 3xTg-RV mice [genotype, $\mathrm{F}(1,42)=28.88, \mathrm{p}<0.0001$; and treatment, $\mathrm{F}(1,42)=6.349$, p = 0.0156]. In the Dark \& Light box test, 3xTg-Ct mice presented a higher anxiety response compared to NoTg mice (Fig. 1d-e). Resveratrol administration increased, in both mouse, strains the number of entries into the lit area (Fig. 1d) [genotype, $\mathrm{F}(1,42)=11.89, \mathrm{p}=0.0013$; and treatment, $\mathrm{F}(1,42)=5.027, \mathrm{p}=0.0303$ ] and the time spent in the lit area (Fig. 1e) [genotype, $\mathrm{F}(1,42)=9.360, \mathrm{p}=0.0039$; and treatment, $\mathrm{F}(1,42)=4.844, \mathrm{p}=0.0333$ ].

\section{Resveratrol administration induced beneficial effects on cognitive behavior}

Ten-month resveratrol treatment induced a significant protective effect against the AD-like pathology involved in learning and memory capacities (Fig. 2a-f). Cognition was preserved in 12-month-old 3xTg-RV mice, in addition to inducing cognitive enhancement effects in NoTg-RV mice. In the NOR test, 3xTg-Ct mice exhibited a deficit of recognition memory, while NoTg-RV and 3xTg-RV mice increased their capacity to remember familiar objects at $2 \mathrm{~h}$ (Fig. 2b) [genotype, $\mathrm{F}(1,36)=4.195, \mathrm{p}=0.0479$; and treatment, $\mathrm{F}(1,36)=8.826, \mathrm{p}=0.0053$ ] and at $24 \mathrm{~h}(\mathrm{Fig}$. 2c) [treatment, $\mathrm{F}(1,36)=6.759, \mathrm{p}=0.0134$; and interaction genotype $\times$ treatment, $\mathrm{F}(1,36)=4.256, \mathrm{p}=0.0464$ ]. In the MWM test, the distances covered to locate the platform decreased along the 6 days of place-task acquisition (Fig. 2d) in 3xTg-RV mice, similar to NoTg mice; however, two-way repeated measures ANOVA did not show significant differences between groups. Nevertheless, in learning retrieval, 3xTg-Ct mice swam at random in the pool unaware of the former position of the escape platform, while both NoTg groups and that of the 3xTg-RV mice remembered the quadrant where the platform was situated (Fig. 2e) [genotype, $F(1,42)=5.537, \mathrm{p}=0.0234$; and interaction genotype $\times$ treatment, $\mathrm{F}(1,42)=6.645, \mathrm{p}=0.0135]$, indicating better memory response after resveratrol treatment. In addition, resveratrol administration increased swimming speed in both strains (fig. 2f) [treatment, $F(1,42)=4.081, p=0.0498$ ] .

\section{Resveratrol administration induced neuroprotective effects against amyloid- $\beta$ pathology}

Analysis of immunoblotting from hippocampus tissue showed higher protein levels of total APP (Fig. 3a) in 3xTg-AD mice as compared with NoTg mice [genotype, $\mathrm{F}(1,20)=48.59, \mathrm{p}<0.0001$ ], as expected. Furthermore, the levels of $\mathrm{A} \beta$ peptides, such as APP-CTF (Fig. 3b) [genotype, $F(1,20)=41.45$, p $<0.0001$; treatment, $F(1,20)=8.680, p=0.0080$; and interaction genotype $\times$ treatment, $\mathrm{F}(1,20)=6.687, \mathrm{p}=0.0177$ ], $\mathrm{A} \beta$ 6e10 (Fig. 3c) [genotype, $\mathrm{F}(1,15)=10.45, \mathrm{p}=$ 0.0056; treatment, $\mathrm{F}(1,15)=6.976, \mathrm{p}=0.0185$; and interaction genotype $\times$ treatment, $\mathrm{F}(1,15)=4.709, \mathrm{p}=0.0465]$, and sAPP $\beta$ (Fig. 3d) [genotype, $\mathrm{F}(1,23)=4.528, \mathrm{p}=0.0443$; and interaction genotype $\times$ treatment, $\mathrm{F}(1,23)=9.954, \mathrm{p}=$ 0.0044], were increased to a higher degree in 3xTg-Ct compared to NoTg mice, as characterized for AD pathogenesis. Resveratrol treatment induced a decrease in amyloid pathology, by a recovery of the APP-CTF (Fig. 3b), A $\beta$ 6e10 (Fig. 
3c), and sAPP $\beta$ (Fig. 3d) protein levels in 3xTg-RV mice, due to a decrease of BACE1 secretase levels (Fig. 3e) [treatment, $\mathrm{F}(1,19)=4.993, \mathrm{p}=0.0377$ ] and the increase of the neprilysin protease (Fig. 3f) [treatment, $\mathrm{F}(1,20)=5.334$, $\mathrm{p}=0.0317$ ] in both strains. These results confirm the effect of resveratrol on $A \beta$ pathology mitigation. The attenuation of the amyloidogenic pathway and the increased proteostasis exerted an effect on both strains treated with resveratrol; however, no significant changes were observed in the levels of the neuroprotector sAPP $\alpha$ peptide (Supplementary Fig. 1a). Resveratrol increased secretase ADAM10 levels with borderline statistical significance (Supplementary Fig. 1b) [treatment, $\mathrm{F}(1,16)=4.218, \mathrm{p}=0.0567$ ]. Protease IDE was reduced in 3xTg-AD mice, but resveratrol did not change levels (Supplementary Fig. 1c) [genotype, $F(1,14)=4.789$, $p=0.0461$ ].

\section{Resveratrol administration induced neuroprotective effects against tau pathology}

Analysis of immunoblotting from hippocampal tissue revealed elevated protein levels of total tau (Fig. 3g) in 3xTg-AD mice as compared with NoTg mice [genotype, $\mathrm{F}(1,20)=24.36, \mathrm{p}<0.0001$ ], as expected. The protein levels of $\mathrm{p}$-tau (Fig. 3h) [genotype, $\mathrm{F}(1,24)=10.72, \mathrm{p}=0.0032$; treatment, $\mathrm{F}(1,24)=10.11, \mathrm{p}=0.0040$; and interaction genotype $\times$ treatment, $\mathrm{F}(1,24)=5.313, \mathrm{p}=0.0301$ ], and of ac-tau (Fig. 3i) [genotype, $\mathrm{F}(1,25)=12.53, \mathrm{p}=0.0016$; treatment, $\mathrm{F}(1,25)=8.924, \mathrm{p}=0.0062$; and interaction genotype $\times$ treatment, $\mathrm{F}(1,25)=5.562, \mathrm{p}=0.0265]$ were increased to a greater degree in 3xTg-Ct compared to NoTg mice, as characterized for AD pathogenesis. Resveratrol treatment protected against tau pathology, in that it normalized p-tau (Fig. 3h) protein levels in 3xTg-RV mice, due to a decrease of ac-tau (Fig. 3i) protein levels in 3xTg-RV mice. Deacetylation of tau protein allows it to be degraded by the UPS. These results confirm the effect of resveratrol on tau pathology mitigation.

\section{Resveratrol administration enhanced ubiquitin-proteasome system activity} Immunoblotting analysis demonstrated higher Hsp70 protein levels (Fig. 4a) [genotype, $\mathrm{F}(1,20)=35.84$, p < 0.0001; treatment, $\mathrm{F}(1,20)=6.283, \mathrm{p}=0.0209$; and interaction genotype $\times$ treatment, $\mathrm{F}(1,20)=7.517, \mathrm{p}=0.0126 \mathrm{]}$ and ubiquitinated proteins levels (Fig. 4b) [genotype, $F(1,18)=5.867, p=0.0262$; treatment, $F(1,18)=10.53$, $p=0.0045$; and interaction genotype $\times$ treatment, $F(1,18)=6.450, p=0.0205$ ] in 3xTg-Ct compared to the hippocampus of NoTg mice. Resveratrol treatment restored Hsp70 (Fig. 4a) and ubiquitinated (Fig. 4b) protein levels in 3xTg-RV mice. Moreover, resveratrol treatment induced an enhancement of proteasome 20S core subunits levels (Fig. 4c) [treatment, $\mathrm{F}(1,28)=12.34, \mathrm{p}=0.0015]$ in the hippocampus of NoTg-RV and $3 \times \mathrm{xT}-\mathrm{RV}$ mice. A tendency to a decrease in proteasome protein levels in 3xTg-Ct mice did not reach significance. Besides, resveratrol also induced enhancement of proteasome 20S core subunits levels (Fig. 4d) [treatment, $F(1,20)=11.02, p=0.0034$ ] in the cerebral cortex of both strains. Accordingly, resveratrol treatment induced an increase of trypsin-like activity (Fig. 4e) [treatment, $\mathrm{F}(1,29)=$ 7.638, $\mathrm{p}=0.0098]$ in the cerebral cortex of both strains, but no changes were detected in chymotrypsin-like (Supplementary Fig. 2a) and caspase-like activity (Supplementary Fig. 2b). These results showed the neuroprotective effects of resveratrol for aberrant proteins disposal by enhancement of the brain proteasome function.

\section{Resveratrol administration activates SIRT1 pathway regulators}

Immunoblotting analysis did not show significant variations of SIRT1 protein levels in the hippocampus of both strains, or after resveratrol treatment (Fig. 5a). However, SIRT1 activity was confirmed by the diminution of p53 acetylated in both strains after resveratrol treatment, indicative of SIRT1 deacetylation action (Fig. 5b) [treatment, $\mathrm{F}(1,20)=9.208$, p $=0.0065$ ] . Moreover, resveratrol treatment incremented p-AMPK protein levels (Fig. 5c) [treatment, $F(1,23)=8.867, \mathrm{p}$ 
$251=0.0067]$ in both strains, which subsequently produces an increase of the substrate $\mathrm{NAD}^{+}$, indicative of SIRT1 pathway 252 activation. Resveratrol promoted the increase of p-CREB (Fig. 5d) [treatment, $F(1,20)=15.75, p=0.0008$ ] by SIRT1 253 pathway in both strains. Moreover, PGC-1 $\alpha$ protein levels were lower in 3xTg-AD compared to NoTg mice, indicative 254 of mitochondria dysfunction (Fig. 5e); however, resveratrol administration increased protein levels in both strains 255 [genotype, $\mathrm{F}(1,23)=8.937, \mathrm{p}=0.0065$; treatment, $\mathrm{F}(1,23)=7.419, \mathrm{p}=0.0121$ ].

257 Resveratrol administration does not modulate neurotrophism or plasticity.

258 Immunoblotting demonstrated that PSD95 (Supplementary Fig. 3a) [genotype, $F(1,16)=21.79, \mathrm{p}=0.0003$ ], and 259 Synaptophysin (Supplementary Fig. 3b) [genotype, $F(1,23)=5.960, p=0.0227$ ] protein levels were higher in NoTg as compared with 3xTg-AD hippocampal tissue. However, resveratrol treatment had no effect, and protein levels were 261 unchanged. 


\section{Discussion}

Chronic administration of resveratrol in the 3xTg-AD mouse model of $\mathrm{AD}$, and in normal NoTg mice, confirmed its potential usefulness for the treatment and prevention of $\mathrm{AD}$, and further extended previous mechanisms in findings from in vitro $[38,57,58]$ and in vivo studies $[20,22,23,26,59,60]$.

Our results showed that resveratrol administration induced total protection against cognitive loss in 3xTg-AD mice and memory enhancement in control mice, in hippocampus-based tests of learning and memory. The hippocampus is an area selectively affected by $\mathrm{AD}$ [61], and the deterioration of hippocampal circuits contributes greatly to the devastating effects of memory loss in the disease [62]. Several regions of cerebral cortex are also deeply affected by AD pathology [63]. Both hippocampus and cerebral cortex shown accumulation of $A \beta$ and $p$-tau and neurodegenerative changes in 12 months old 3xTg-AD mice [53].

The spatial learning and memory analyzed in the MWM test are considered to be associated with optimal functioning of hippocampal circuits $[64,65]$. Untreated $3 \mathrm{xTg}-\mathrm{AD}$ mice exhibited deficient learning and impaired retention in the MWM task, as reported previously [52]. This task, which is dependent on the dorsal hippocampus [66], revealed totally protection in 3xTg-AD mice by means of resveratrol administration. Furthermore, 3xTg-AD mice showed impairment of recognition memory evaluated by the NOR test [67], a task involving the hippocampus and brain cortex regions $[68,69]$. Recognition memory was also preserved by resveratrol administration in 3xTg-AD mice. The neuroprotection of resveratrol against cognitive impairment in 3xTg-AD mice confirmed previous studies in the SAMP8 mouse model of pathological aging and AD [26,59] and in APP/PS1 AD transgenic mice [22]. Furthermore, recognition memory was generally improved by resveratrol, demonstrating cognitive enhancement in NoTg mice. Benefits of resveratrol administration were also proven by reversal of the abnormal behaviors included in the BPSD phenotype, which comprise very prevalent neuropsychiatric symptoms in patients with $\mathrm{AD}$ [70]. In these non-cognitive behaviors, resveratrol also exhibited beneficial effects in NoTg mice, which is indicative of enhanced well-being, such as increased exploration and decreased anxiety behaviors. Considering the results of cognitive and non-cognitive behavior, a preventive and therapeutic effect of resveratrol against $\mathrm{AD}$ dementia has been demonstrated. The benefits in neuronal activity demonstrated in control-strain mice suggest an enhancement in brain resilience that would decrease the risk of AD.

Analysis of brain pathological changes in 3xTg-AD mice demonstrated that resveratrol induced a decrease in amyloid and tau pathologies to levels similar to those in the control strain. Only higher levels of APP and total tau were observed in all 3xTg-AD mouse groups compared to NoTg mice, in agreement to their transgene expression [51]. Western blot immunodetection results of amyloidogenic fragments (A $\beta$ and CTF) were conclusive of total protection. The fight against the cerebral excess of $A \beta$ is one of the main objectives of therapies in clinical studies [71]. The origin of the excess of $A \beta$ in the brain is not known, although both increased generation and unbalanced degradation are assumed [72]. The non-amyloidogenic pathway appears to be neuroprotective, while the amyloidogenic pathway generates neurotoxic $A \beta$ peptides [73]. Both pathways compete with each other, since increasing $\alpha$-secretase activity reduces production of the $\mathrm{A} \beta$ peptides [74,75]. BACE1 is regarded as a key target for therapeutic interventions in AD because it is one of the main responsible for A $\beta$ generation in the brain [76,77]. Targeted deletion of BACE1 in APP transgenic mice completely abolishes the production and deposition of $A \beta$ and also rescues memory deficits [78]. We found a reduction of the amyloidogenic secretase BACE1 by resveratrol in both 3xTg-AD and NoTg strains, thus indicating a shift to the non-amyloidogenic pathway of APP processing. Peptide SAPP $\beta$ was higher only in 3xTg-AD and resveratrol reduced the protein levels. One of the most important amyloid degrading enzymes is neprilysin, which plays a major 
the anti-amyloidogenic effect of resveratrol in both strains. Gene or cell therapy mediated increase of neprilysin is sufficient to ameliorate AD-like phenotypes in several mouse models [79-81]. Our results suggest that resveratrol reduced A $\beta$ load through the decrease of amyloidogenic secretase BACE1 and by means of the increase of amyloiddegrading enzyme neprilysin levels. Supplementation of resveratrol also induced a trend toward increasing the levels of ADAM10 in both strains, altogether contributing to neuroprotection and cerebral resilience. SIRT1 decreases A $\beta$ production [30,82,83]; therefore, activation of SIRT1 might at least partially mediate the anti-amyloid pathological effects of resveratrol. Resveratrol revealed outstanding protection against tau pathology in $3 \times \mathrm{Tg}-\mathrm{AD}$ mice. Tau pathology is proposed to be triggered by amyloid pathology in the AD brain [84]. However, 3xTg-AD neurons, in addition to the APP and PS1 familial AD genes, express a human tauopathy gene, thus stressing tau pathology in this mouse model. Tau is one of the therapeutic targets in $\mathrm{AD}$ [85]. We found that the increase of p-tau levels in 3xTg-AD mice was paralleled by an increase in tau acetylation. Acetylation of lysine residues has been reported as a novel modification in the brain tissue of patients with $\mathrm{AD}$ and familial tauopathies [86-88]. Resveratrol administration reduced p-tau levels in 3xTg-AD mice, which may occur through the deacetylation of the tau protein by SIRT1, thereby favoring degradation of p-tau by the proteasome pathway. It is known that activation of SIRT1 pathway has a positive effect on the reduction of p-tau formation [86] and mice with a SIRT1 deletion show an accumulation of ac-tau in the brain $[86,88]$.

The enhancement of proteolysis systems shown here by resveratrol may be chief in both prevention and therapy against $\mathrm{AD}$ and in neurodegenerative diseases coursing with the accumulation of aberrant proteins. We found a normalization of Hsp70 and ubiquitin levels in 3xTg-AD and a significant increase of proteasome levels and enzymatic activity in both NoTg and 3xTg-AD mice. UPS is the major proteolytic system that degrades aberrant proteins, including A $\beta$ and p-tau [50]. Loss of proteasome activity increases the risk of $\mathrm{AD}$, representing a clear link between this neurodegenerative disease and the aging process [40]. Functional proteasome degrades ubiquitin-tagged misfolded or aggregated proteins. Our results are in agreement with the previous observation that resveratrol promotes the intracellular degradation of $A \beta$ in cell lines by a mechanism that implicates the proteasome [38]. SIRT1 is known to be involved in the maintenance of quality control of proteins mediated by UPS in vitro [30,89]; however, an effect of resveratrol on UPS activation had not been reported previously in vivo. The chaperone Hsp70 is involved in the degradation of aberrant proteins through interaction with CHIP and the ubiquitin E3 ligase [48,90,91]. Resveratrol induced a further decrease of Hsp70, in agreement with SIRT1 regulation [48], and also normalized ubiquitinated protein levels in 3xTg-AD mice, suggesting a recovery of UPS functionality. Proteasome 20S core subunits levels were decreased in 3xTg-AD mice, indicating impairment of the proteasome function, in agreement with previous results in $\mathrm{AD}$ brain tissue [92] and in hippocampal homogenates of 3xTg-AD mice [93]. Resveratrol enhanced the levels of proteasome $20 \mathrm{~S}$ core subunits in both hippocampus and cortex tissue of NoTg and 3xTg-AD mice, and trypsin proteasomal activity in cerebral cortex of both strains of mice, suggesting an enhancement of UPS functionality. Some neurofibrillary tangles of p-tau are ubiquitinated [94,95], and neuronal death appears to be the end-point for neurofibrillary degeneration [96]. The increased yield of proteasome protein levels in brain tissue of 3xTg-AD mice would lead to the total degradation of aberrant $A \beta$ and $\mathrm{p}$-tau proteins, so that ubiquitinated proteins and Hsp70 were restored to baseline levels. Resveratrol also induced proteostasis enhancement in NoTg mice; thus, this is, to our knowledge, the first time reported that resveratrol increases proteasome function and ameliorates AD-like pathology in vivo. We highlight the increase of both the proteasome and neprilysin in the strain of NoTg mice, which would induce resilience against the accumulation of abnormal proteins.

344 Although resveratrol was initially shown to directly activate SIRT1 in an assay utilizing a fluorophore-linked substrate [97], recent studies have shown that resveratrol indirectly activates SIRT1 due to its effect on cAMP signaling [34]. 
SIRT1 is a nuclear localization protein [98] that, catalyzes the deacetylation of histones and several transcription factors through the consumption of the substrate $\mathrm{NAD}^{+}[29,99]$. Resveratrol is thought to elicit its beneficial effects through upregulation of the AMPK/SIRT1 pathway [100-102]. It is suggested that resveratrol enhances AMPK activity, which in turn increases $\mathrm{NAD}^{+}$concentration, resulting in the activation of SIRT1 [34,35,103]. Accordingly, AMPK-deficient mice showed to be resistant to the metabolic effects of resveratrol [101]. We found higher levels of p-AMPK in the hippocampus of both resveratrol-treated groups of mice; however, we did not observe changes in SIRT1 protein levels. In the inducible p25 transgenic mouse model of $\mathrm{AD}$ and tauopathies, introduction of resveratrol directly into the brain ventricles prevented learning impairment, reduced hippocampal neurodegeneration, and decreased acetylation of the SIRT1 substrate p53 [23]. SIRT1 induces neuroprotective effects against AD pathology through regulating the acetylation homeostasis of key proteins [29]. Accordingly, a decrease in p53 acetylation indicates SIRT1 activation in mouse hippocampus.

The cyclic-AMP responsive element binding protein (CREB) is a basic leucine zipper transcription factor and a downstream target of ERK signaling during hippocampal-dependent learning [104]. The transcription of several downstream neuroprotective molecules is regulated by p-CREB. Deficiencies in CREB signaling have been linked to neurodegenerative processes and AD [105]. In previous studies, elevated p-CREB levels were found in the hippocampal CA1 region of resveratrol-treated rats [106]. Furthermore, it has been demonstrated that resveratrol can modulate learning and memory function by modulating SIRT1 and regulating p-CREB expression [60]. SIRT1 can regulate mitochondrial biogenesis, contributing to the maintenance of functional mitochondria [107]. It is also well-established that SIRT1 regulates the activity and acetylation status of PGC-1 $\alpha[103,108,109]$, and many studies have pointed out the ability of resveratrol to upregulate PGC-1 $\alpha$ activity[110], which results in beneficial changes in the mitochondrial function [100,111,112]. Previous studies indicate the deficiencies of mitochondrial complexes in 3xTg-AD mice [54] and elevated levels of oxidative lesions and alterations of antioxidant enzymes [52,113]. In this regard, we cannot discard some contribution of direct antioxidant mechanisms of reveratrol or other protective effects of this pleiotropic molecule [14,114]. Mitochondrial dysfunction is a molecular marker of aging that establishes a connection between aging and the risk of AD [115,116]. Mitochondrial dysfunction can be ameliorated by inducing PGC-1 $\alpha$ via resveratrolmediated modulation of AMPK [117,118]. The enhancement of AMPK [35], PGC-1 $\alpha$ [119] and CREB [60] pathways in all the mice treated with resveratrol corroborates the beneficial changes in mitochondrial function and plasticity processes, which will induce effector ways of protecting mitochondria, thus increasing the resilience of the brain. 


\section{Conclusions}

376 In summary, diet supplementation with resveratrol led to complete protection against memory loss in 3xTg-AD mice 377 and to cognitive enhancement in healthy NoTg mice. Furthermore, resveratrol improved non-cognitive behaviors 378 indicative of well-being in both mouse strains. Analysis of resveratrol administration in AD and healthy mice led to the 379 uncovering of the following novel resveratrol mechanisms in vivo: i) activation of neprilysin and downregulation of 380 BACE1, which reduces amyloid load; ii) enhancement of UPS, which leads to a reduction of aberrant amyloid and tau proteins, and iii) upregulation of AMPK/SIRT1 pathways, leading to an increase of PGC-1 $\alpha$ and CREB. A schematic representation of the proposed mechanisms activated by resveratrol in this study is depicted in Fig. 6. The results depicted here suggest resveratrol-induced activation of SIRT1 as the main pathway inducing potent neuroprotective effects. This natural polyphenol has a potential in $\mathrm{AD}$ prevention by increasing brain resilience against aberrant proteins.

Acknowledgements This study was supported by grant SAF2016-77703 and SAF2016-81716-REDC from Spanish MINECO and European Development Fund; 2017-SGR-106 from AGAUR and the CERCA Programme / Generalitat de Catalunya. We acknowledge the use of mice derived from the colony established by Dr Lydia Giménez-Llort at the Universitat Autònoma de Barcelona with progenitors provided by Dr Frank M LaFerla, University of California Irvine.

Compliance with Ethical Standards

Conflict of Interest The authors declare that they have no conflict of interest. 
Fig. 1 Resveratrol treatment induced protection against BPSD-like behavior. Total number of rearings (a) and distance covered (b) in the Open field test. Latency of first-hole exploration (c) in the Boissier's 4 hole-board test. Number of entries in the lit area (d), and time spent in the lit area (e) in the Dark \& Light box test. Values are mean \pm SEM ( $n=10$ 14). Statistical analysis: Two-way ANOVA, effect of genotype $\& \& p<0.01$ and $\& \& \& p<0.001$; and effect of treatment $\$ \mathrm{p}<0.05$ and $\$ \mathrm{p}<0.01$

Fig. 2 Resveratrol administration induced protection against cognitive loss. NOR test at times $0 \mathrm{~h}(\mathbf{a}), 2 \mathrm{~h}(\mathbf{b})$, and $24 \mathrm{~h}$ (c). MWM test with distances covered to reach platform (d), distance covered in platform quadrant after removal (e), and swimming speed $(\mathbf{f})$. Values are mean \pm SEM $(n=8$-14). Statistical analysis: $\mathbf{c}$, e Two-way ANOVA, *p < 0.05 and *** $\mathrm{p}<0.001$ compared to NoTg mice; \#p $<0.05$ and \#\#p $<0.01$ compared to control treatment; $\mathbf{d}$ Two-way repeated measures ANOVA; $\mathbf{b}, \mathbf{f}$ Two-way ANOVA, effect of genotype $\& \mathrm{p}<0.05$; and effect of treatment $\$ \mathrm{p}<0.05$ and $\$ \$ \mathrm{p}<$ 0.01

Fig. 3 Resveratrol treatment protects against $A \beta$ and tau pathology in hippocampus. Western blot analysis of total APP (a), APP-CTF (b), A $\beta$ fragment (c), sAPP $\beta$ (d), BACE1 (e), neprilysin (f), total tau (g), p-tau (h) and ac-tau (i) in the hippocampus of 3xTg-AD and NoTg mice. Values are mean \pm SEM $(n=4-8)$. Statistical analysis: a, d, $\mathbf{f}, \mathbf{g}$ Two-way ANOVA, effect of genotype \&\&\&p < 0.001; and effect of treatment $\$ \mathrm{p}<0.05 ; \mathbf{b}, \mathbf{c}, \mathbf{e}, \mathbf{h}, \mathbf{i}$ Two-way ANOVA, **p $<$ 0.01 and $* * * \mathrm{p}<0.001$ compared to NoTg mice; $\# \mathrm{p}<0.05$ and \#\#p $<0.01$ compared to control treatment

Fig. 4 Resveratrol administration enhances the activity of the ubiquitin-proteasome system. Protein analysis of Hsp70 (a), ubiquitinated proteins (b) and proteasome 20S core subunits (c) in the hippocampus of 3xTg-AD and NoTg mice. Protein analysis of proteasome $20 \mathrm{~S}$ core subunits (d) and proteasome trypsin-like activity (e) in the cerebral cortex tissue of 3xTg-AD and NoTg mice. Values are mean \pm SEM $(n=5-11)$. Statistical analysis: a, b Two-way ANOVA, $* * p<0.01$ and $* * * p<0.001$ compared to NoTg mice; \#\#p < 0.01 compared to control treatment; $\mathbf{c}$, d, e Two-way ANOVA, effect of treatment $\$ \$ p<0.01$

Fig. 5 Resveratrol administration activates SIRT1 pathway by activation of p-AMPK. Protein analysis of SIRT1 (a), ratio of p53 acetylated to total p53 (b), ratio of p-AMPK to total AMPK (c), ratio of p-CREB to total CREB (d), and PGC-1 $\alpha$ (e) in the hippocampus of 3xTg-AD and NoTg mice. Values are mean \pm SEM $(n=5-7)$. Statistical analysis: Two-way ANOVA, effect of genotype $\& \& p<0.01$; and effect of treatment $\$ p<0.05, \$ \$ p<0.01$ and $\$ \$ p p<0.001$

Fig. 6 Proposed pathways involved in the neuroprotective effects of resveratrol administration, leading to a reduction in AD-like pathology through proteostasis enhancement. See text for discussion of mechanisms. Abbreviations: Ac, acetylated; $\mathrm{A} \beta$, amyloid- $\beta$; $\mathrm{AD}$, Alzheimer's disease; ADAM10, a disintegrin and metalloproteinase 10; AMPK, adenosine monophosphate-activated protein kinase; BACE1, beta-site APP cleaving enzyme 1; CREB, cAMP response element-binding protein; PGC-1 $\alpha$, peroxisome proliferator-activated receptor- $\gamma$ coactivator $1 \alpha$; -tau, hyperphosphorylated tau; UPS, ubiquitin proteasome system. 
1. World Alzheimer Report (2016) Improving healthcare for people living with dementia.

Alzheimer's Disease International (ADI), London

2. Reitz C, Brayne C, Mayeux R (2011) Epidemiology of Alzheimer disease. Nat Rev Neurol 7 (3):137-152. doi:10.1038/nrneurol.2011.2

3. Lane CA, Hardy J, Schott JM (2018) Alzheimer's disease. Eur J Neurol 25 (1):59-70. doi:10.1111/ene.13439

4. Hardy J, Selkoe DJ (2002) The amyloid hypothesis of Alzheimer's disease: progress and problems on the road to therapeutics. Science 297 (5580):353-356. doi:10.1126/science.1072994 5. Selkoe DJ (2011) Alzheimer's disease. Cold Spring Harb Perspect Biol 3 (7). doi:10.1101/cshperspect.a004457

6. Salomone S, Caraci F, Leggio GM, Fedotova J, Drago F (2012) New pharmacological strategies for treatment of Alzheimer's disease: focus on disease modifying drugs. Br J Clin Pharmacol 73 (4):504-517. doi:10.1111/j.1365-2125.2011.04134.x

7. Kumar A, Singh A, Ekavali (2015) A review on Alzheimer's disease pathophysiology and its management: an update. Pharmacol Rep 67 (2):195-203. doi:10.1016/j.pharep.2014.09.004

8. Burns J, Yokota T, Ashihara H, Lean ME, Crozier A (2002) Plant foods and herbal sources of resveratrol. J Agric Food Chem 50 (11):3337-3340

9. Baur JA, Sinclair DA (2006) Therapeutic potential of resveratrol: the in vivo evidence. Nat Rev Drug Discov 5 (6):493-506. doi:10.1038/nrd2060

10. Malhotra A, Bath S, Elbarbry F (2015) An Organ System Approach to Explore the Antioxidative, Anti-Inflammatory, and Cytoprotective Actions of Resveratrol. Oxid Med Cell Longev 2015:803971. doi:10.1155/2015/803971

11. Novelle MG, Wahl D, Dieguez C, Bernier M, de Cabo R (2015) Resveratrol supplementation: Where are we now and where should we go? Ageing Res Rev 21:1-15.

doi:10.1016/j.arr.2015.01.002

12. Sun AY, Wang Q, Simonyi A, Sun GY (2010) Resveratrol as a therapeutic agent for neurodegenerative diseases. Mol Neurobiol 41 (2-3):375-383. doi:10.1007/s12035-010-8111-y 13. Rege SD, Geetha T, Griffin GD, Broderick TL, Babu JR (2014) Neuroprotective effects of resveratrol in Alzheimer disease pathology. Front Aging Neurosci 6:218.

doi:10.3389/fnagi.2014.00218

14. Ahmed T, Javed S, Javed S, Tariq A, Samec D, Tejada S, Nabavi SF, Braidy N, Nabavi SM (2017) Resveratrol and Alzheimer's Disease: Mechanistic Insights. Mol Neurobiol 54 (4):26222635. doi:10.1007/s12035-016-9839-9

15. Sawda C, Moussa C, Turner RS (2017) Resveratrol for Alzheimer's disease. Ann N Y Acad Sci 1403 (1):142-149. doi:10.1111/nyas.13431

16. Turner RS, Thomas RG, Craft S, van Dyck CH, Mintzer J, Reynolds BA, Brewer JB, Rissman RA, Raman R, Aisen PS, Alzheimer's Disease Cooperative S (2015) A randomized, double-blind, placebo-controlled trial of resveratrol for Alzheimer disease. Neurology 85 (16):1383-1391. doi:10.1212/WNL.0000000000002035

17. Moussa C, Hebron M, Huang X, Ahn J, Rissman RA, Aisen PS, Turner RS (2017) Resveratrol regulates neuro-inflammation and induces adaptive immunity in Alzheimer's disease. $\mathrm{J}$

Neuroinflammation 14 (1):1. doi:10.1186/s12974-016-0779-0

18. Witte AV, Kerti L, Margulies DS, Floel A (2014) Effects of resveratrol on memory performance, hippocampal functional connectivity, and glucose metabolism in healthy older adults. J Neurosci 34 (23):7862-7870. doi:10.1523/JNEUROSCI.0385-14.2014

19. Evans HM, Howe PR, Wong RH (2017) Effects of Resveratrol on Cognitive Performance, Mood and Cerebrovascular Function in Post-Menopausal Women; A 14-Week Randomised Placebo-Controlled Intervention Trial. Nutrients 9 (1). doi:10.3390/nu9010027 20. Karuppagounder SS, Pinto JT, Xu H, Chen HL, Beal MF, Gibson GE (2009) Dietary supplementation with resveratrol reduces plaque pathology in a transgenic model of Alzheimer's disease. Neurochem Int 54 (2):111-118. doi:10.1016/j.neuint.2008.10.008 21. Vingtdeux V, Giliberto L, Zhao H, Chandakkar P, Wu Q, Simon JE, Janle EM, Lobo J, Ferruzzi MG, Davies P, Marambaud P (2010) AMP-activated protein kinase signaling activation by resveratrol modulates amyloid-beta peptide metabolism. J Biol Chem 285 (12):9100-9113. doi:10.1074/jbc.M109.060061 
22. Porquet D, Grinan-Ferre C, Ferrer I, Camins A, Sanfeliu C, Del Valle J, Pallas M (2014) Neuroprotective role of trans-resveratrol in a murine model of familial Alzheimer's disease. $\mathrm{J}$ Alzheimers Dis 42 (4):1209-1220. doi:10.3233/JAD-140444 23. Kim D, Nguyen MD, Dobbin MM, Fischer A, Sananbenesi F, Rodgers JT, Delalle I, Baur JA, Sui G, Armour SM, Puigserver P, Sinclair DA, Tsai LH (2007) SIRT1 deacetylase protects against neurodegeneration in models for Alzheimer's disease and amyotrophic lateral sclerosis. EMBO J 26 (13):3169-3179. doi:10.1038/sj.emboj.7601758

24. Barger JL, Kayo T, Vann JM, Arias EB, Wang J, Hacker TA, Wang Y, Raederstorff D, Morrow JD, Leeuwenburgh C, Allison DB, Saupe KW, Cartee GD, Weindruch R, Prolla TA (2008) A low dose of dietary resveratrol partially mimics caloric restriction and retards aging parameters in mice. PLoS One 3 (6):e2264. doi:10.1371/journal.pone.0002264

25. Albani D, Polito L, Batelli S, De Mauro S, Fracasso C, Martelli G, Colombo L, Manzoni C, Salmona M, Caccia S, Negro A, Forloni G (2009) The SIRT1 activator resveratrol protects SK-NBE cells from oxidative stress and against toxicity caused by alpha-synuclein or amyloid-beta (142) peptide. J Neurochem 110 (5):1445-1456. doi:10.1111/j.1471-4159.2009.06228.x 26. Porquet D, Casadesus G, Bayod S, Vicente A, Canudas AM, Vilaplana J, Pelegri C, Sanfeliu C, Camins A, Pallas M, del Valle J (2013) Dietary resveratrol prevents Alzheimer's markers and increases life span in SAMP8. Age (Dordr) 35 (5):1851-1865. doi:10.1007/s11357-012-9489-4 27. Haigis MC, Sinclair DA (2010) Mammalian sirtuins: biological insights and disease relevance. Annu Rev Pathol 5:253-295. doi:10.1146/annurev.pathol.4.110807.092250

28. Donmez $G$ (2012) The neurobiology of sirtuins and their role in neurodegeneration. Trends Pharmacol Sci 33 (9):494-501. doi:10.1016/j.tips.2012.05.007

29. Herskovits AZ, Guarente L (2014) SIRT1 in neurodevelopment and brain senescence. Neuron 81 (3):471-483. doi:10.1016/j.neuron.2014.01.028

30. Corpas R, Revilla S, Ursulet S, Castro-Freire M, Kaliman P, Petegnief V, Gimenez-Llort L, Sarkis C, Pallas M, Sanfeliu C (2017) SIRT1 Overexpression in Mouse Hippocampus Induces Cognitive Enhancement Through Proteostatic and Neurotrophic Mechanisms. Mol Neurobiol 54 (7):5604-5619. doi:10.1007/s12035-016-0087-9

31. Borra MT, Smith BC, Denu JM (2005) Mechanism of human SIRT1 activation by resveratrol. J Biol Chem 280 (17):17187-17195. doi:10.1074/jbc.M501250200

32. Beher D, Wu J, Cumine S, Kim KW, Lu SC, Atangan L, Wang M (2009) Resveratrol is not a direct activator of SIRT1 enzyme activity. Chem Biol Drug Des 74 (6):619-624. doi:10.1111/j.17470285.2009.00901.x

33. Bitterman JL, Chung JH (2015) Metabolic effects of resveratrol: addressing the controversies. Cell Mol Life Sci 72 (8):1473-1488. doi:10.1007/s00018-014-1808-8

34. Park SJ, Ahmad F, Philp A, Baar K, Williams T, Luo H, Ke H, Rehmann H, Taussig R, Brown AL, Kim MK, Beaven MA, Burgin AB, Manganiello V, Chung JH (2012) Resveratrol ameliorates aging-related metabolic phenotypes by inhibiting cAMP phosphodiesterases. Cell 148 (3):421-433. doi:10.1016/j.cell.2012.01.017

35. Price NL, Gomes AP, Ling AJ, Duarte FV, Martin-Montalvo A, North BJ, Agarwal B, Ye L, Ramadori G, Teodoro JS, Hubbard BP, Varela AT, Davis JG, Varamini B, Hafner A, Moaddel R, Rolo AP, Coppari R, Palmeira CM, de Cabo R, Baur JA, Sinclair DA (2012) SIRT1 is required for AMPK activation and the beneficial effects of resveratrol on mitochondrial function. Cell Metab 15 (5):675-690. doi:10.1016/j.cmet.2012.04.003

36. Jang JH, Surh YJ (2003) Protective effect of resveratrol on beta-amyloid-induced oxidative PC12 cell death. Free Radic Biol Med 34 (8):1100-1110

37. Chiang MC, Nicol CJ, Cheng YC (2018) Resveratrol activation of AMPK-dependent pathways is neuroprotective in human neural stem cells against amyloid-beta-induced inflammation and oxidative stress. Neurochem Int 115:1-10. doi:10.1016/j.neuint.2017.10.002

38. Marambaud P, Zhao H, Davies P (2005) Resveratrol promotes clearance of Alzheimer's disease amyloid-beta peptides. J Biol Chem 280 (45):37377-37382. doi:10.1074/jbc.M508246200 39. Regitz C, Fitzenberger E, Mahn FL, Dussling LM, Wenzel U (2016) Resveratrol reduces amyloid-beta (Abeta(1)(-)(4)(2))-induced paralysis through targeting proteostasis in an Alzheimer model of Caenorhabditis elegans. Eur J Nutr 55 (2):741-747. doi:10.1007/s00394-015-0894-1 40. Vilchez D, Saez I, Dillin A (2014) The role of protein clearance mechanisms in organismal ageing and age-related diseases. Nat Commun 5:5659. doi:10.1038/ncomms6659 
41. Xin SH, Tan L, Cao X, Yu JT, Tan L (2018) Clearance of Amyloid Beta and Tau in Alzheimer's Disease: from Mechanisms to Therapy. Neurotox Res. doi:10.1007/s12640-018-9895-1

42. Scheper W, Nijholt DA, Hoozemans JJ (2011) The unfolded protein response and proteostasis in Alzheimer disease: preferential activation of autophagy by endoplasmic reticulum stress.

Autophagy 7 (8):910-911

43. Gerakis Y, Hetz C (2018) Emerging roles of ER stress in the etiology and pathogenesis of Alzheimer's disease. FEBS J 285 (6):995-1011. doi:10.1111/febs.14332

44. Hashimoto S, Saido TC (2018) Critical review: involvement of endoplasmic reticulum stress in the aetiology of Alzheimer's disease. Open Biol 8 (4). doi:10.1098/rsob.180024

45. Karpova A, Mikhaylova M, Thomas U, Knopfel T, Behnisch T (2006) Involvement of protein synthesis and degradation in long-term potentiation of Schaffer collateral CA1 synapses. J Neurosci 26 (18):4949-4955. doi:10.1523/JNEUROSCI.4573-05.2006

46. Fonseca R, Vabulas RM, Hartl FU, Bonhoeffer T, Nagerl UV (2006) A balance of protein synthesis and proteasome-dependent degradation determines the maintenance of LTP. Neuron 52 (2):239-245. doi:10.1016/j.neuron.2006.08.015

47. Gadhave K, Bolshette N, Ahire A, Pardeshi R, Thakur K, Trandafir C, Istrate A, Ahmed S, Lahkar M, Muresanu DF, Balea M (2016) The ubiquitin proteasomal system: a potential target for the management of Alzheimer's disease. J Cell Mol Med 20 (7):1392-1407.

doi: $10.1111 / \mathrm{jcmm} .12817$

48. Westerheide SD, Anckar J, Stevens SM, Jr., Sistonen L, Morimoto RI (2009) Stress-inducible regulation of heat shock factor 1 by the deacetylase SIRT1. Science 323 (5917):1063-1066. doi:10.1126/science.1165946

49. Groll M, Ditzel L, Lowe J, Stock D, Bochtler M, Bartunik HD, Huber R (1997) Structure of $20 \mathrm{~S}$ proteasome from yeast at $2.4 \mathrm{~A}$ resolution. Nature 386 (6624):463-471. doi:10.1038/386463a0 50. Ciechanover A, Kwon YT (2015) Degradation of misfolded proteins in neurodegenerative diseases: therapeutic targets and strategies. Exp Mol Med 47:e147. doi:10.1038/emm.2014.117 51. Oddo S, Caccamo A, Shepherd JD, Murphy MP, Golde TE, Kayed R, Metherate R, Mattson MP, Akbari Y, LaFerla FM (2003) Triple-transgenic model of Alzheimer's disease with plaques and tangles: intracellular Abeta and synaptic dysfunction. Neuron 39 (3):409-421

52. Garcia-Mesa Y, Colie S, Corpas R, Cristofol R, Comellas F, Nebreda AR, Gimenez-Llort L, Sanfeliu C (2016) Oxidative Stress Is a Central Target for Physical Exercise Neuroprotection Against Pathological Brain Aging. J Gerontol A Biol Sci Med Sci 71 (1):40-49.

doi:10.1093/gerona/glv005

53. Mastrangelo MA, Bowers WJ (2008) Detailed immunohistochemical characterization of temporal and spatial progression of Alzheimer's disease-related pathologies in male tripletransgenic mice. BMC Neurosci 9:81. doi:10.1186/1471-2202-9-81

54. Garcia-Mesa Y, Gimenez-Llort L, Lopez LC, Venegas C, Cristofol R, Escames G, AcunaCastroviejo D, Sanfeliu C (2012) Melatonin plus physical exercise are highly neuroprotective in the 3xTg-AD mouse. Neurobiol Aging 33 (6):1124 e1113-1129.

doi:10.1016/j.neurobiolaging.2011.11.016

55. Corpas R, Hernandez-Pinto AM, Porquet D, Hernandez-Sanchez C, Bosch F, Ortega-Aznar A, Comellas F, de la Rosa EJ, Sanfeliu C (2017) Proinsulin protects against age-related cognitive loss through anti-inflammatory convergent pathways. Neuropharmacology 123:221-232.

doi:10.1016/j.neuropharm.2017.06.014

56. Revilla S, Ursulet S, Alvarez-Lopez MJ, Castro-Freire M, Perpina U, Garcia-Mesa Y, Bortolozzi A, Gimenez-Llort L, Kaliman P, Cristofol R, Sarkis C, Sanfeliu C (2014) Lenti-GDNF gene therapy protects against Alzheimer's disease-like neuropathology in 3xTg-AD mice and MC65 cells. CNS Neurosci Ther 20 (11):961-972. doi:10.1111/cns.12312

57. Conte A, Pellegrini S, Tagliazucchi D (2003) Synergistic protection of PC12 cells from betaamyloid toxicity by resveratrol and catechin. Brain Res Bull 62 (1):29-38

58. Cristofol R, Porquet D, Corpas R, Coto-Montes A, Serret J, Camins A, Pallas M, Sanfeliu C (2012) Neurons from senescence-accelerated SAMP8 mice are protected against frailty by the sirtuin 1 promoting agents melatonin and resveratrol. J Pineal Res 52 (3):271-281.

doi:10.1111/j.1600-079X.2011.00939.X

59. Liu GS, Zhang ZS, Yang B, He W (2012) Resveratrol attenuates oxidative damage and ameliorates cognitive impairment in the brain of senescence-accelerated mice. Life Sci 91 (1718):872-877. doi:10.1016/j.lfs.2012.08.033 
60. Wang R, Zhang Y, Li J, Zhang C (2017) Resveratrol ameliorates spatial learning memory impairment induced by Abeta1-42 in rats. Neuroscience 344:39-47.

doi:10.1016/j.neuroscience.2016.08.051

61. Mu Y, Gage FH (2011) Adult hippocampal neurogenesis and its role in Alzheimer's disease. Mol Neurodegener 6:85. doi:10.1186/1750-1326-6-85

62. Apostolova LG, Zarow C, Biado K, Hurtz S, Boccardi M, Somme J, Honarpisheh H, Blanken AE, Brook J, Tung S, Lo D, Ng D, Alger JR, Vinters HV, Bocchetta M, Duvernoy H, Jack CR, Jr., Frisoni GB, Segmentation E-AWGotHPfMH (2015) Relationship between hippocampal atrophy and neuropathology markers: a 7T MRI validation study of the EADC-ADNI Harmonized Hippocampal Segmentation Protocol. Alzheimers Dement 11 (2):139-150. doi:10.1016/j.jalz.2015.01.001 63. Raskin J, Cummings J, Hardy J, Schuh K, Dean RA (2015) Neurobiology of Alzheimer's Disease: Integrated Molecular, Physiological, Anatomical, Biomarker, and Cognitive Dimensions. Curr Alzheimer Res 12 (8):712-722

64. Riedel G, Micheau J, Lam AG, Roloff EL, Martin SJ, Bridge H, de Hoz L, Poeschel B, McCulloch J, Morris RG (1999) Reversible neural inactivation reveals hippocampal participation in several memory processes. Nat Neurosci 2 (10):898-905. doi:10.1038/13202

65. Laeremans A, Sabanov V, Ahmed T, Nys J, Van de Plas B, Vinken K, Woolley DG, Gantois I, D'Hooge R, Arckens L, Balschun D (2015) Distinct and simultaneously active plasticity mechanisms in mouse hippocampus during different phases of Morris water maze training. Brain Struct Funct 220 (3):1273-1290. doi:10.1007/s00429-014-0722-z

66. D'Hooge R, De Deyn PP (2001) Applications of the Morris water maze in the study of learning and memory. Brain Res Brain Res Rev 36 (1):60-90

67. Slevin M, Matou S, Zeinolabediny Y, Corpas R, Weston R, Liu D, Boras E, Di Napoli M, Petcu E, Sarroca S, Popa-Wagner A, Love S, Font MA, Potempa LA, Al-Baradie R, Sanfeliu C, Revilla S, Badimon L, Krupinski J (2015) Monomeric C-reactive protein--a key molecule driving development of Alzheimer's disease associated with brain ischaemia? Sci Rep 5:13281. doi:10.1038/srep13281 68. Assini FL, Duzzioni M, Takahashi RN (2009) Object location memory in mice: pharmacological validation and further evidence of hippocampal CA1 participation. Behav Brain Res 204 (1):206211. doi:10.1016/j.bbr.2009.06.005

69. Broadbent NJ, Gaskin S, Squire LR, Clark RE (2010) Object recognition memory and the rodent hippocampus. Learn Mem 17 (1):5-11. doi:10.1101/lm.1650110

70. Shin IS, Carter M, Masterman D, Fairbanks L, Cummings JL (2005) Neuropsychiatric symptoms and quality of life in Alzheimer disease. Am J Geriatr Psychiatry 13 (6):469-474. doi:10.1176/appi.ajgp.13.6.469

71. Selkoe DJ, Hardy J (2016) The amyloid hypothesis of Alzheimer's disease at 25 years. EMBO Mol Med 8 (6):595-608. doi:10.15252/emmm.201606210

72. Agostinho P, Pliassova A, Oliveira CR, Cunha RA (2015) Localization and Trafficking of Amyloid-beta Protein Precursor and Secretases: Impact on Alzheimer's Disease. J Alzheimers Dis 45 (2):329-347. doi:10.3233/JAD-142730

73. Vetrivel KS, Thinakaran G (2006) Amyloidogenic processing of beta-amyloid precursor protein in intracellular compartments. Neurology 66 (2 Suppl 1):S69-73.

doi:10.1212/01.wnl.0000192107.17175.39

74. Nitsch RM, Slack BE, Wurtman RJ, Growdon JH (1992) Release of Alzheimer amyloid precursor derivatives stimulated by activation of muscarinic acetylcholine receptors. Science 258 (5080):304-307

75. Postina R, Schroeder A, Dewachter I, Bohl J, Schmitt U, Kojro E, Prinzen C, Endres K, Hiemke C, Blessing M, Flamez P, Dequenne A, Godaux E, van Leuven F, Fahrenholz F (2004) A disintegrin-metalloproteinase prevents amyloid plaque formation and hippocampal defects in an Alzheimer disease mouse model. J Clin Invest 113 (10):1456-1464. doi:10.1172/JCI20864 76. Haniu M, Denis P, Young Y, Mendiaz EA, Fuller J, Hui JO, Bennett BD, Kahn S, Ross S, Burgess T, Katta V, Rogers G, Vassar R, Citron M (2000) Characterization of Alzheimer's beta secretase protein BACE. A pepsin family member with unusual properties. J Biol Chem 275 (28):21099-21106. doi:10.1074/jbc.M002095200

77. Vassar R (2004) BACE1: the beta-secretase enzyme in Alzheimer's disease. J Mol Neurosci 23 (1-2):105-114. doi:10.1385/JMN:23:1-2:105 
662

663

664

665

666

667

668

669

670

671

672

673

674

675

676

677

678

679

680

681

682

683

684

685

686

687

688

689

690

691

692

693

694

695

696

697

698

699

700

701

702

703

704

705

706

707

708

709

710

711

712

713

714

715

716

717

78. Ohno M, Cole SL, Yasvoina M, Zhao J, Citron M, Berry R, Disterhoft JF, Vassar R (2007) BACE1 gene deletion prevents neuron loss and memory deficits in 5XFAD APP/PS1 transgenic mice. Neurobiol Dis 26 (1):134-145. doi:10.1016/j.nbd.2006.12.008

79. Spencer B, Marr RA, Rockenstein E, Crews L, Adame A, Potkar R, Patrick C, Gage FH, Verma IM, Masliah E (2008) Long-term neprilysin gene transfer is associated with reduced levels of intracellular Abeta and behavioral improvement in APP transgenic mice. BMC Neurosci 9:109. doi:10.1186/1471-2202-9-109

80. Blurton-Jones M, Spencer B, Michael S, Castello NA, Agazaryan AA, Davis JL, Muller FJ, Loring JF, Masliah E, LaFerla FM (2014) Neural stem cells genetically-modified to express neprilysin reduce pathology in Alzheimer transgenic models. Stem Cell Res Ther 5 (2):46. doi:10.1186/scrt440

81. Devi L, Ohno M (2015) A combination Alzheimer's therapy targeting BACE1 and neprilysin in 5XFAD transgenic mice. Mol Brain 8:19. doi:10.1186/s13041-015-0110-5

82. Lee HR, Shin HK, Park SY, Kim HY, Lee WS, Rhim BY, Hong KW, Kim CD (2014) Cilostazol suppresses beta-amyloid production by activating a disintegrin and metalloproteinase 10 via the upregulation of SIRT1-coupled retinoic acid receptor-beta. J Neurosci Res 92 (11):1581-1590. doi:10.1002/jnr.23421

83. Saftig P, Lichtenthaler SF (2015) The alpha secretase ADAM10: A metalloprotease with multiple functions in the brain. Prog Neurobiol 135:1-20. doi:10.1016/j.pneurobio.2015.10.003 84. Lloret A, Fuchsberger T, Giraldo E, Vina J (2015) Molecular mechanisms linking amyloid beta toxicity and Tau hyperphosphorylation in Alzheimers disease. Free Radic Biol Med 83:186-191. doi:10.1016/j.freeradbiomed.2015.02.028

85. Avila J, Pallas N, Bolos M, Sayas CL, Hernandez F (2016) Intracellular and extracellular microtubule associated protein tau as a therapeutic target in Alzheimer disease and other tauopathies. Expert Opin Ther Targets 20 (6):653-661. doi:10.1517/14728222.2016.1131269 86. Min SW, Cho SH, Zhou Y, Schroeder S, Haroutunian V, Seeley WW, Huang EJ, Shen Y, Masliah E, Mukherjee C, Meyers D, Cole PA, Ott M, Gan L (2010) Acetylation of tau inhibits its degradation and contributes to tauopathy. Neuron 67 (6):953-966.

doi:10.1016/j.neuron.2010.08.044

87. Irwin DJ, Cohen TJ, Grossman M, Arnold SE, Xie SX, Lee VM, Trojanowski JQ (2012)

Acetylated tau, a novel pathological signature in Alzheimer's disease and other tauopathies. Brain 135 (Pt 3):807-818. doi:10.1093/brain/aws013

88. Min SW, Chen X, Tracy TE, Li Y, Zhou Y, Wang C, Shirakawa K, Minami SS, Defensor E, Mok SA, Sohn PD, Schilling B, Cong X, Ellerby L, Gibson BW, Johnson J, Krogan N, Shamloo M, Gestwicki J, Masliah E, Verdin E, Gan L (2015) Critical role of acetylation in tau-mediated neurodegeneration and cognitive deficits. Nat Med 21 (10):1154-1162. doi:10.1038/nm.3951 89. Tomita T, Hamazaki J, Hirayama S, McBurney MW, Yashiroda H, Murata S (2015) Sirt1deficiency causes defective protein quality control. Sci Rep 5:12613. doi:10.1038/srep12613 90. Petrucelli L, Dickson D, Kehoe K, Taylor J, Snyder H, Grover A, De Lucia M, McGowan E, Lewis J, Prihar G, Kim J, Dillmann WH, Browne SE, Hall A, Voellmy R, Tsuboi Y, Dawson TM, Wolozin B, Hardy J, Hutton M (2004) CHIP and Hsp70 regulate tau ubiquitination, degradation and aggregation. Hum Mol Genet 13 (7):703-714. doi:10.1093/hmg/ddh083

91. Magrane J, Smith RC, Walsh K, Querfurth HW (2004) Heat shock protein 70 participates in the neuroprotective response to intracellularly expressed beta-amyloid in neurons. J Neurosci 24

(7):1700-1706. doi:10.1523/JNEUROSCI.4330-03.2004

92. Keller JN, Hanni KB, Markesbery WR (2000) Impaired proteasome function in Alzheimer's disease. J Neurochem 75 (1):436-439

93. Tseng BP, Green KN, Chan JL, Blurton-Jones M, LaFerla FM (2008) Abeta inhibits the proteasome and enhances amyloid and tau accumulation. Neurobiol Aging 29 (11):1607-1618. doi:10.1016/j.neurobiolaging.2007.04.014

94. Perry G, Friedman R, Shaw G, Chau V (1987) Ubiquitin is detected in neurofibrillary tangles and senile plaque neurites of Alzheimer disease brains. Proc Natl Acad Sci U S A 84 (9):30333036

95. Wang JZ, Grundke-lqbal I, lqbal K (2007) Kinases and phosphatases and tau sites involved in Alzheimer neurofibrillary degeneration. Eur J Neurosci 25 (1):59-68. doi:10.1111/j.1460-

9568.2006.05226.x 
96. Cras P, Smith MA, Richey PL, Siedlak SL, Mulvihill P, Perry G (1995) Extracellular neurofibrillary tangles reflect neuronal loss and provide further evidence of extensive protein crosslinking in Alzheimer disease. Acta Neuropathol 89 (4):291-295 97. Howitz KT, Bitterman KJ, Cohen HY, Lamming DW, Lavu S, Wood JG, Zipkin RE, Chung P, Kisielewski A, Zhang LL, Scherer B, Sinclair DA (2003) Small molecule activators of sirtuins extend Saccharomyces cerevisiae lifespan. Nature 425 (6954):191-196. doi:10.1038/nature01960 98. Michishita E, Park JY, Burneskis JM, Barrett JC, Horikawa I (2005) Evolutionarily conserved and nonconserved cellular localizations and functions of human SIRT proteins. Mol Biol Cell 16 (10):4623-4635. doi:10.1091/mbc.E05-01-0033 99. Johnson S, Imai SI (2018) NAD (+) biosynthesis, aging, and disease. F1000Res 7:132. doi:10.12688/f1000research.12120.1

100. Lagouge M, Argmann C, Gerhart-Hines Z, Meziane H, Lerin C, Daussin F, Messadeq N, Milne J, Lambert P, Elliott P, Geny B, Laakso M, Puigserver P, Auwerx J (2006) Resveratrol improves mitochondrial function and protects against metabolic disease by activating SIRT1 and PGC-1alpha. Cell 127 (6):1109-1122. doi:10.1016/j.cell.2006.11.013 101. Um JH, Park SJ, Kang H, Yang S, Foretz M, McBurney MW, Kim MK, Viollet B, Chung JH (2010) AMP-activated protein kinase-deficient mice are resistant to the metabolic effects of resveratrol. Diabetes 59 (3):554-563. doi:10.2337/db09-0482

102. Hubbard BP, Sinclair DA (2014) Small molecule SIRT1 activators for the treatment of aging and age-related diseases. Trends Pharmacol Sci 35 (3):146-154. doi:10.1016/j.tips.2013.12.004 103. Canto C, Gerhart-Hines Z, Feige JN, Lagouge M, Noriega L, Milne JC, Elliott PJ, Puigserver $\mathrm{P}$, Auwerx J (2009) AMPK regulates energy expenditure by modulating NAD+ metabolism and SIRT1 activity. Nature 458 (7241):1056-1060. doi:10.1038/nature07813 104. Sindreu CB, Scheiner ZS, Storm DR (2007) Ca2+ -stimulated adenylyl cyclases regulate ERK-dependent activation of MSK1 during fear conditioning. Neuron 53 (1):79-89. doi:10.1016/j.neuron.2006.11.024 105. Saura CA, Valero J (2011) The role of CREB signaling in Alzheimer's disease and other cognitive disorders. Rev Neurosci 22 (2):153-169. doi:10.1515/RNS.2011.018

106. Li Z, Fang F, Wang Y, Wang $L$ (2016) Resveratrol protects CA1 neurons against focal cerebral ischemic reperfusion-induced damage via the ERK-CREB signaling pathway in rats. Pharmacol Biochem Behav 146-147:21-27. doi:10.1016/j.pbb.2016.04.007 107. Tang BL (2016) Sirt1 and the Mitochondria. Mol Cells 39 (2):87-95. doi:10.14348/molcells.2016.2318 108. Rodgers JT, Lerin C, Haas W, Gygi SP, Spiegelman BM, Puigserver P (2005) Nutrient control of glucose homeostasis through a complex of PGC-1alpha and SIRT1. Nature 434 (7029):113-118. doi:10.1038/nature03354

109. Nemoto S, Fergusson MM, Finkel T (2005) SIRT1 functionally interacts with the metabolic regulator and transcriptional coactivator PGC-1\{alpha\}. J Biol Chem 280 (16):16456-16460. doi:10.1074/jbc.M501485200

110. Palomera-Avalos V, Grinan-Ferre C, Izquierdo V, Camins A, Sanfeliu C, Pallas M (2017) Metabolic Stress Induces Cognitive Disturbances and Inflammation in Aged Mice: Protective Role of Resveratrol. Rejuvenation Res 20 (3):202-217. doi:10.1089/rej.2016.1885

111. Canto C, Auwerx J (2009) PGC-1alpha, SIRT1 and AMPK, an energy sensing network that controls energy expenditure. Curr Opin Lipidol 20 (2):98-105. doi:10.1097/MOL.0b013e328328d0a4

112. Valenti D, de Bari L, de Rasmo D, Signorile A, Henrion-Caude A, Contestabile A, Vacca RA (2016) The polyphenols resveratrol and epigallocatechin-3-gallate restore the severe impairment of mitochondria in hippocampal progenitor cells from a Down syndrome mouse model. Biochim Biophys Acta 1862 (6):1093-1104. doi:10.1016/j.bbadis.2016.03.003

113. Garcia-Mesa Y, Lopez-Ramos JC, Gimenez-Llort L, Revilla S, Guerra R, Gruart A, Laferla FM, Cristofol R, Delgado-Garcia JM, Sanfeliu C (2011) Physical exercise protects against Alzheimer's disease in 3xTg-AD mice. J Alzheimers Dis 24 (3):421-454. doi:10.3233/JAD-2011101635

114. Jardim FR, de Rossi FT, Nascimento MX, da Silva Barros RG, Borges PA, Prescilio IC, de Oliveira MR (2018) Resveratrol and Brain Mitochondria: a Review. Mol Neurobiol 55 (3):20852101. doi:10.1007/s12035-017-0448-z 
115. Huang WJ, Zhang X, Chen WW (2016) Role of oxidative stress in Alzheimer's disease. Biomed Rep 4 (5):519-522. doi:10.3892/br.2016.630 116. Cadonic C, Sabbir MG, Albensi BC (2016) Mechanisms of Mitochondrial Dysfunction in Alzheimer's Disease. Mol Neurobiol 53 (9):6078-6090. doi:10.1007/s12035-015-9515-5 117. Chen S, Fan Q, Li A, Liao D, Ge J, Laties AM, Zhang X (2013) Dynamic mobilization of PGC1alpha mediates mitochondrial biogenesis for the protection of RGC-5 cells by resveratrol during serum deprivation. Apoptosis 18 (7):786-799. doi:10.1007/s10495-013-0837-3 118. Banerjee K, Munshi S, Frank DE, Gibson GE (2015) Abnormal Glucose Metabolism in Alzheimer's Disease: Relation to Autophagy/Mitophagy and Therapeutic Approaches. Neurochem Res 40 (12):2557-2569. doi:10.1007/s11064-015-1631-0

119. Sweeney G, Song J (2016) The association between PGC-1alpha and Alzheimer's disease. Anat Cell Biol 49 (1):1-6. doi:10.5115/acb.2016.49.1.1 
A $B$
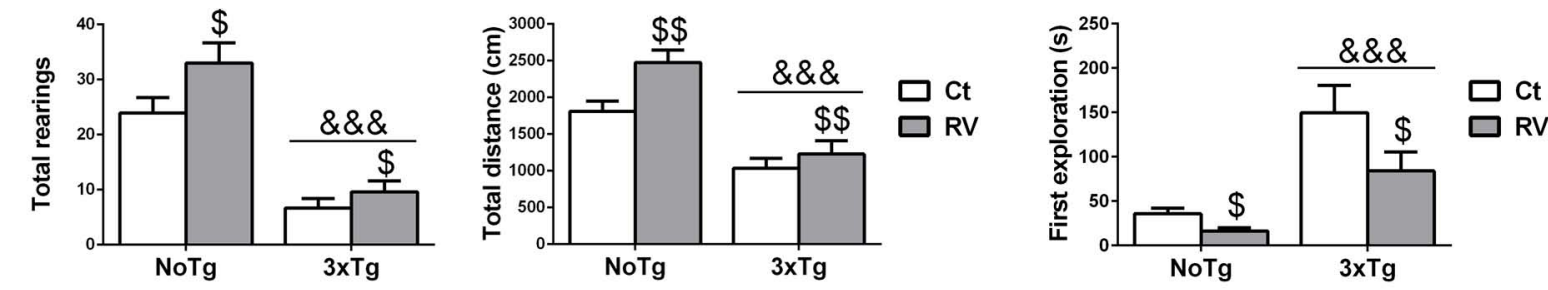

\section{DARK \& LIGHT}

D

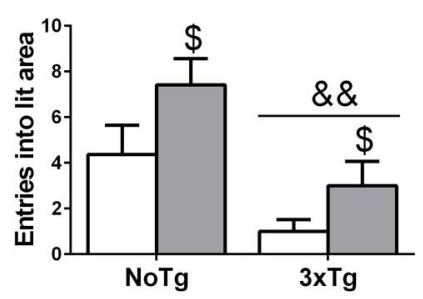

E

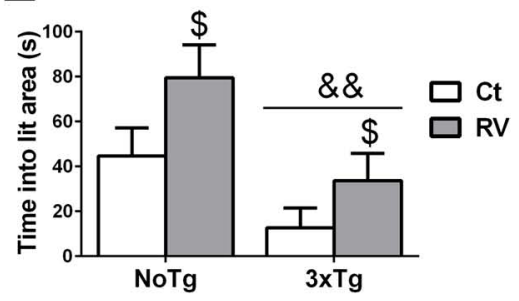



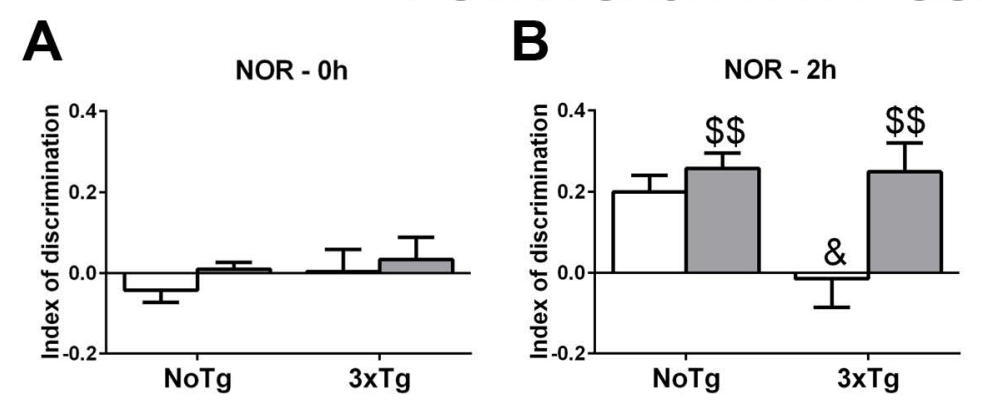

C

NOR - 24h

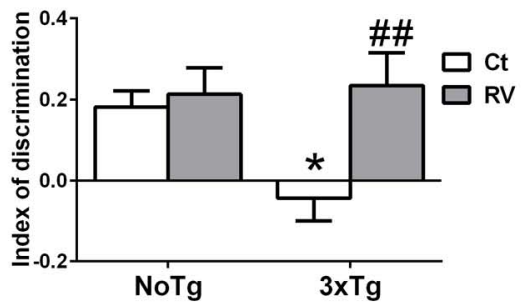

\section{MORRIS WATER MAZE}

D Acquisition task

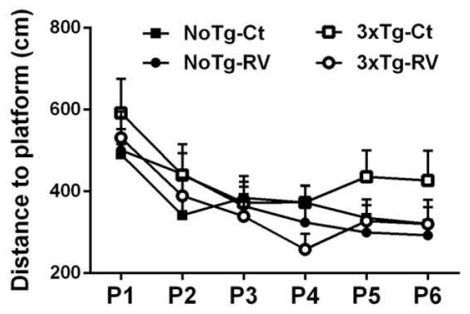

E

Removal test

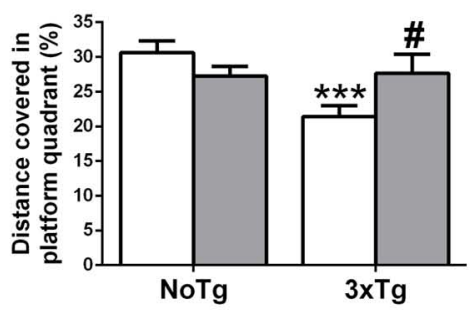

Removal test

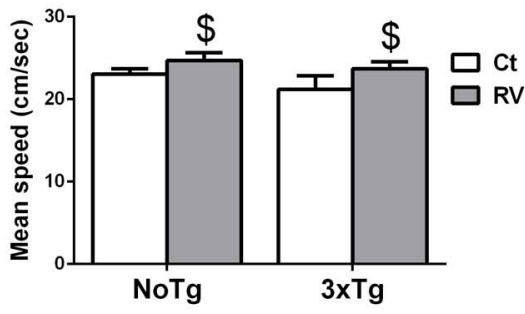




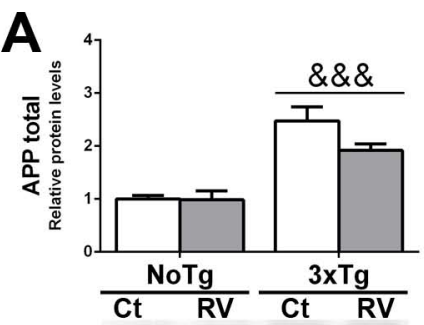

\section{APP}

Actin

D

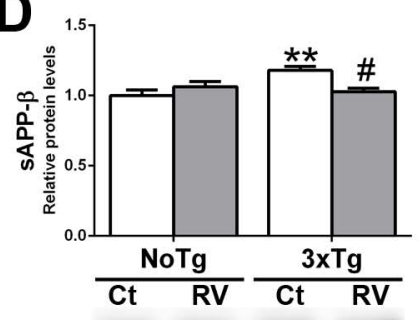

SAPPB

Actin

G

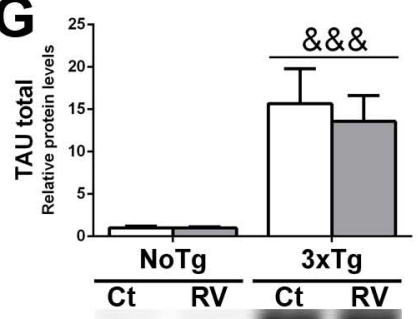

TAU

Actin

AMYLOID- $\beta$ PATHOLOGY

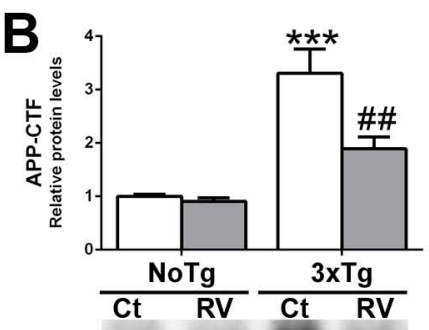

APP-CTF

Actin

E

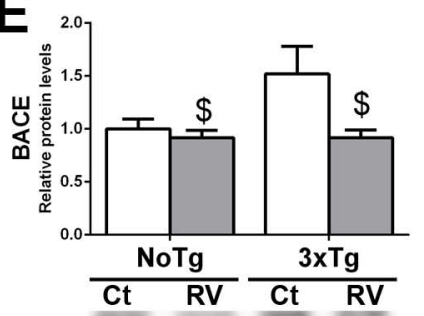

BACE1

Actin

C

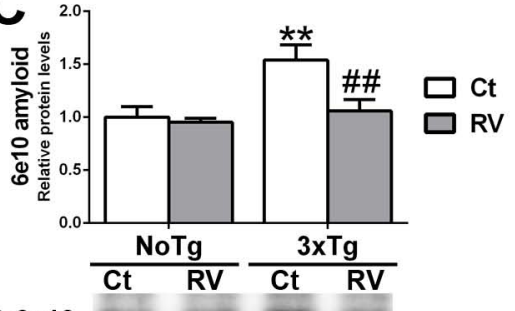

$A B 6 e 10$

Actin

$\mathbf{F}$

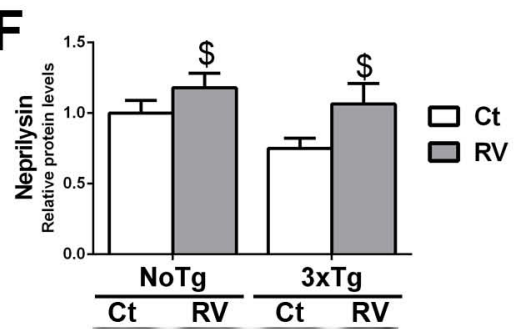

Neprilysin

Tubulin

\section{TAU PATHOLOGY}

H

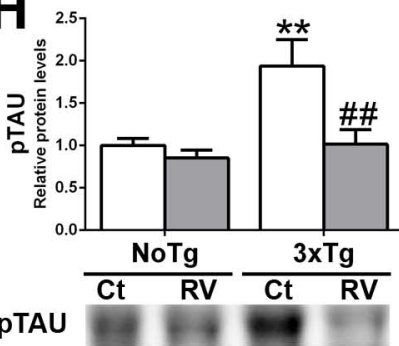

Actin
I

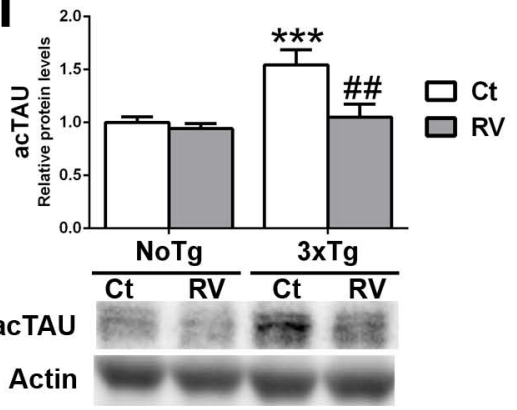




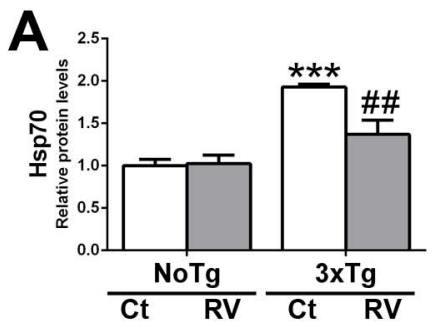

Hsp70

Tubulin

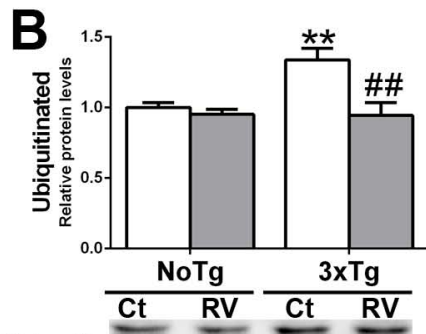

Ubiquit

Tubulin

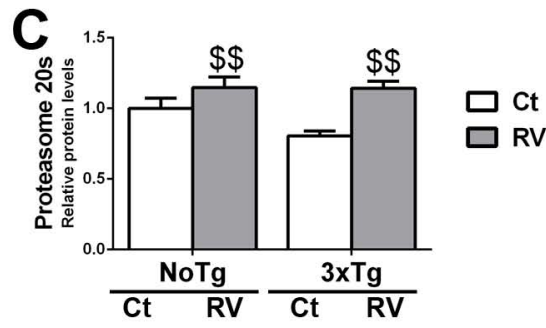

Prot20S

Tubulin
D

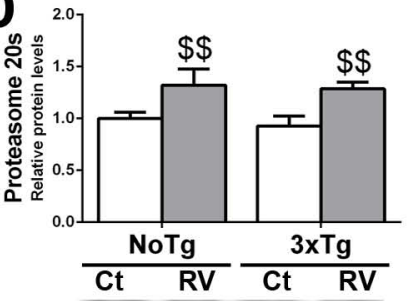

Prot20S

Tubulin

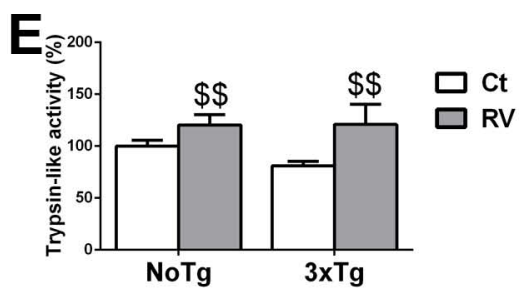



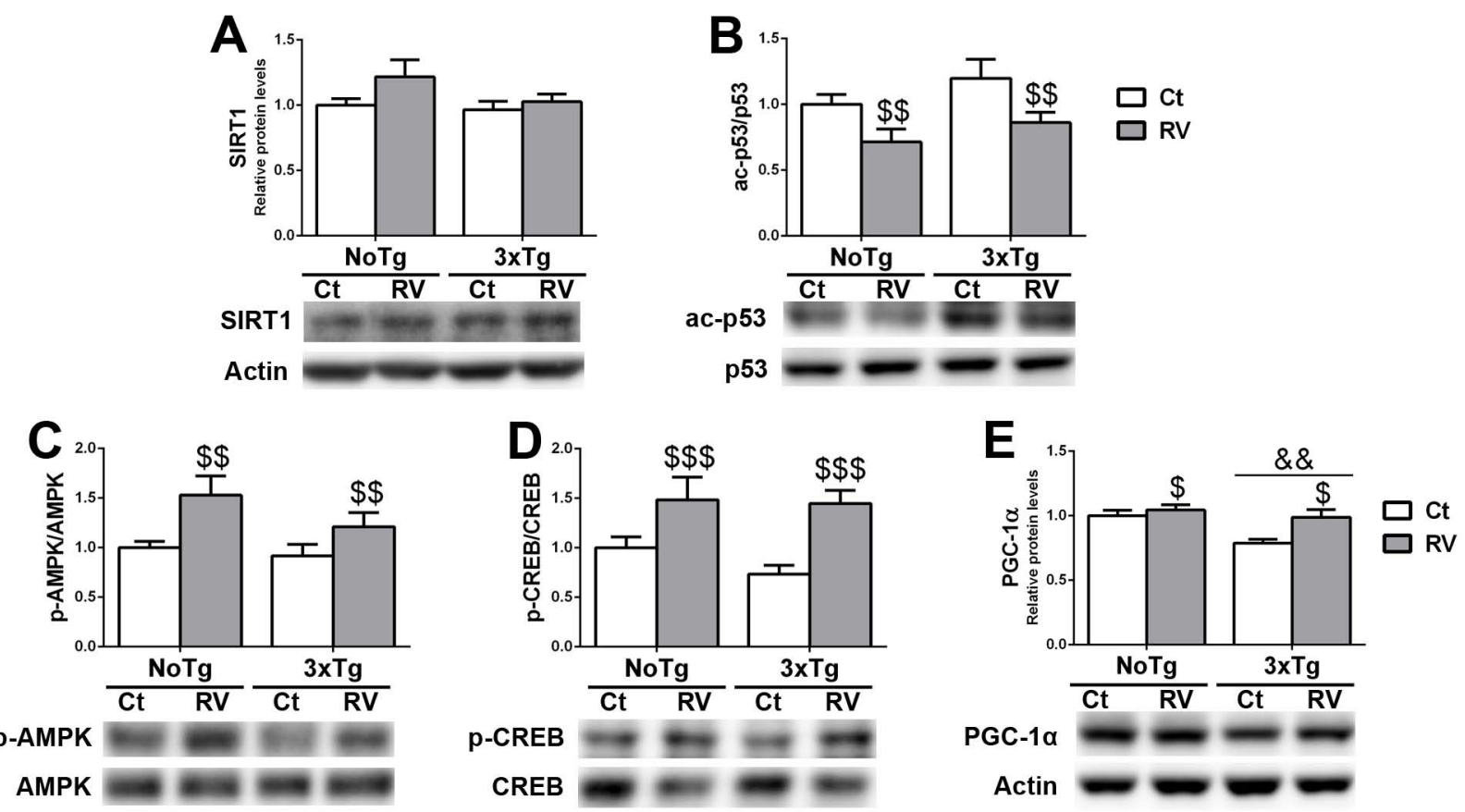


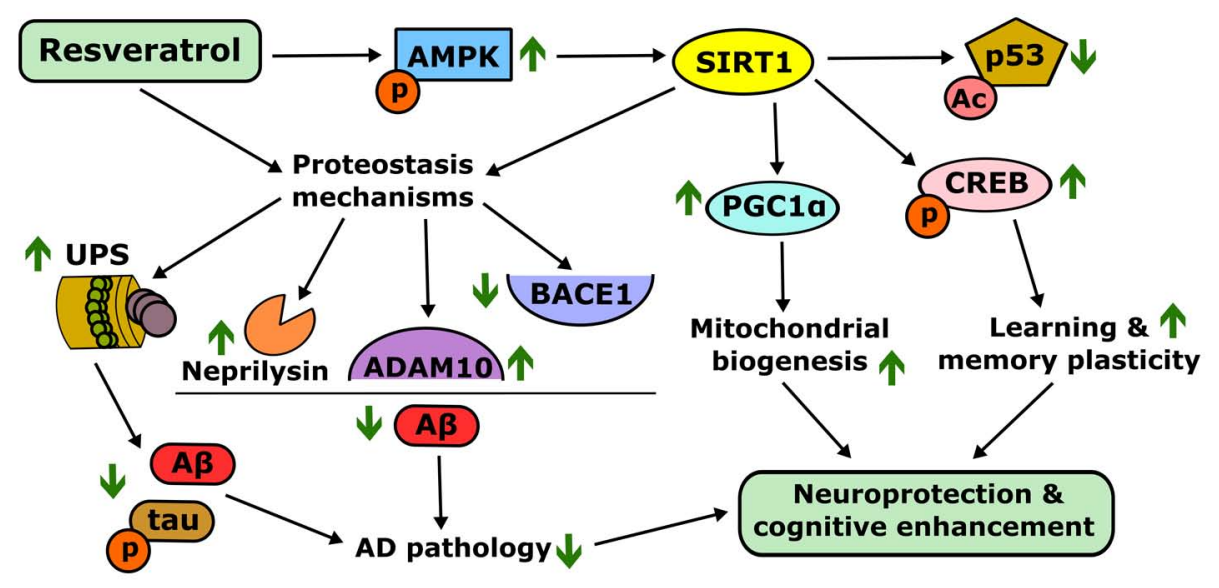




\section{Supplementary Table 1}

List of primary antibodies used in Western blotting (WB)

\begin{tabular}{|c|c|c|c|}
\hline Antibody & Dilution & Source & Catalog № \\
\hline$A \beta$, clone $6 \mathrm{e} 10$ & $1: 1000$ & BioLegend & 803001 \\
\hline sAPPa & $1: 500$ & BioLegend & 813501 \\
\hline SAPPB & $1: 1000$ & BioLegend & 813401 \\
\hline APP-CTF, clone C1/6.1 & $1: 1000$ & Covance & SIG-39152 \\
\hline Actin (20-33) & $1: 10000$ & Sigma & A5060 \\
\hline ADAM10 & $1: 1000$ & Abcam & ab1997 \\
\hline AMPK & $1: 1000$ & Cell Signaling & $2532 S$ \\
\hline p-AMPK (Thr172) & $1: 1000$ & Cell Signaling & $2535 S$ \\
\hline BACE1 & $1: 1000$ & Abcam & ab2077 \\
\hline CREB & $1: 1000$ & Cell Signaling & $9197 S$ \\
\hline p-CREB (Ser133) & $1: 1000$ & Cell Signaling & $9196 S$ \\
\hline Hsp70 (W27) & $1: 2000$ & Calbiochem & HSP01 \\
\hline IDE & $1: 1000$ & Calbiochem & PC730 \\
\hline Neprilysin/CD10 & $1: 1000$ & $R \& D$ system & AF1126 \\
\hline ac-p53, acetyl K382 & $1: 1000$ & Abcam & $a b 37318$ \\
\hline PGC-1a & $1: 500$ & Santa Cruz Biotechnology & sc-13067 \\
\hline Proteasome $20 \mathrm{~S}$ core & $1: 1000$ & Enzo Life Sciences & BML-PW8155 \\
\hline PSD95 & $1: 500$ & Millipore & MAB1598 \\
\hline SIRT1 & $1: 2500$ & Cell Signaling & $2028 s$ \\
\hline Synaptophysin & $1: 10000$ & Dako & A0010 \\
\hline ac-tau, acetyl K280 & $1: 500$ & AnaSpec & 56077 \\
\hline p-tau, clone AT8 & $1: 1000$ & Thermo Scientific & MN1020 \\
\hline Total tau, clone HT7 & $1: 1000$ & Thermo Scientific & MN1000 \\
\hline$\beta$-tubulin & $1: 10000$ & Sigma & T4026 \\
\hline Ubiquitin & $1: 2000$ & Abcam & $a b 137031$ \\
\hline
\end{tabular}




\section{Supplementary figures}
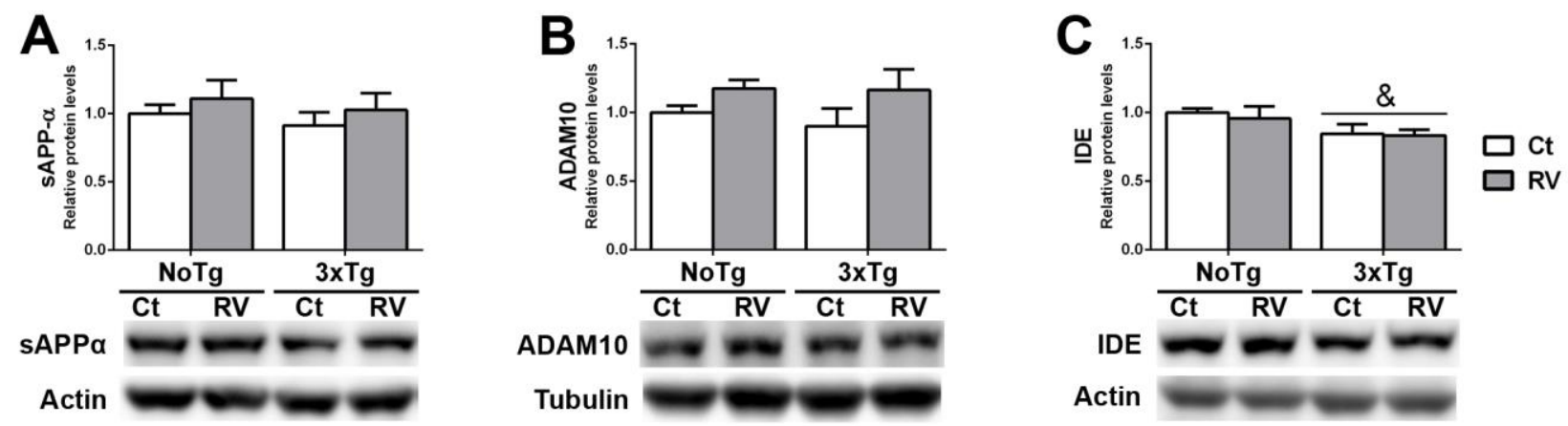

Supplementary Fig. 1 Resveratrol administration has minor effect on the non-amyloidogenic pathway and IDE. Protein analysis of sAPP $\alpha$ peptide (a), ADAM10 (b) and IDE (c) in the hippocampus of 3xTg-AD and NoTg mice. Values are mean \pm SEM $(n=4-7)$. Statistical analysis: Two-way ANOVA, effect of genotype $\& p<0.05$.
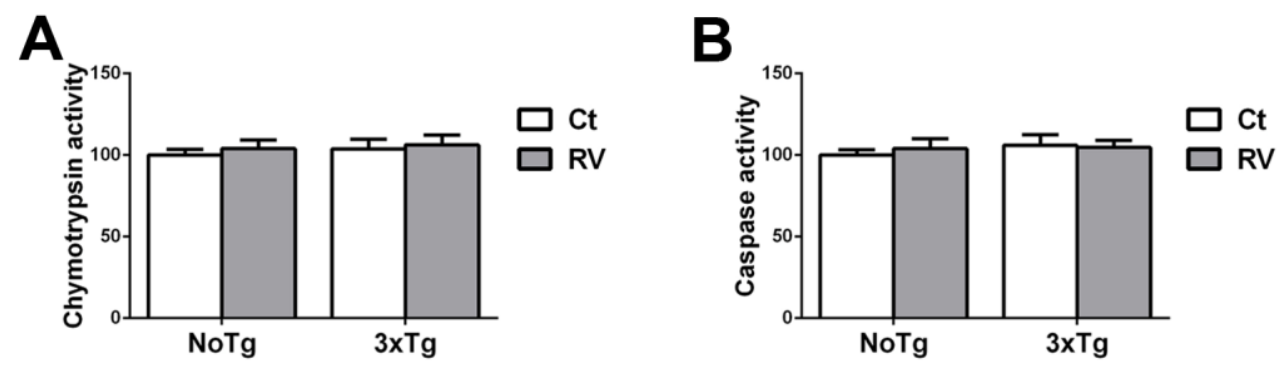

Supplementary Fig. 2 Resveratrol administration does not modulate chymotrypsin-like and caspase-like activity. Chymotrypsin-like activity (a) and Caspase-like activity (b) in the cortex tissue of 3xTg-AD and NoTg mice. Values are mean $\pm \operatorname{SEM}(n=5-11)$.
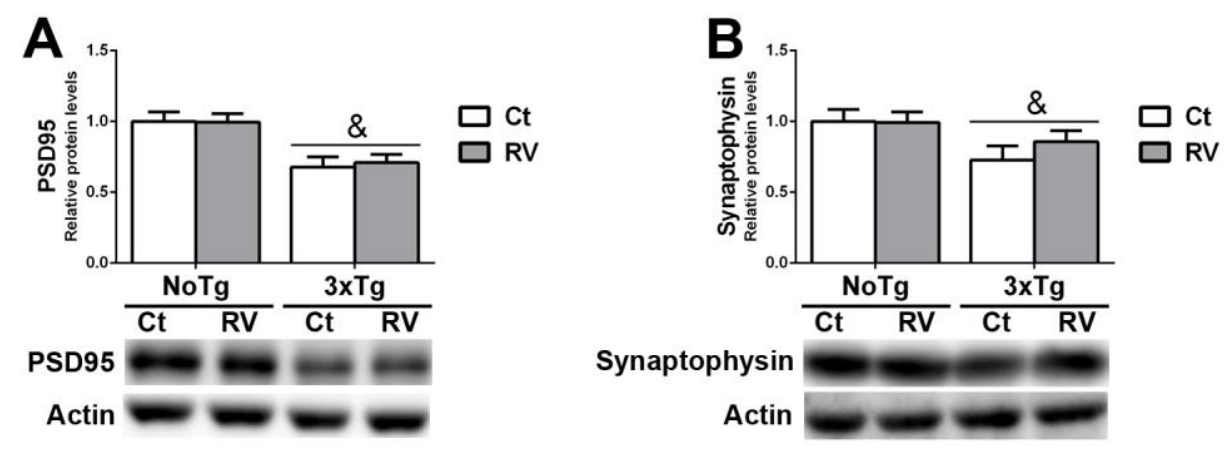

Supplementary Fig. 3 Resveratrol does not modulate neurotrophism or plasticity. Relative protein levels for PSD95 (a) and Synaptophysin (b) in the hippocampus of 3xTg-AD and NoTg mice. Values are mean \pm SEM $(n=5-7)$. Statistical analysis: Two-way ANOVA, effect of genotype $\& p<0.05$. 